in space Research

Elsevier Editorial System(tm) for Advances

Manuscript Draft

Manuscript Number: ASR-D-15-00780R2

Title: Cross-calibrating ALES Envisat and CryoSat-2 Delay-Doppler: A coastal altimetry study in the Indonesian Seas

Article Type: ES - Earth Sciences

Keywords: Coastal Altimetry; SAR altimetry; Indonesia; sea state bias; Cryosat; sea level

Corresponding Author: Mr. Marcello Passaro,

Corresponding Author's Institution: Deutsches Geodätisches Forschungs Institut

First Author: Marcello Passaro

Order of Authors: Marcello Passaro; Salvatore Dinardo; Graham D Quartly; Helen M Snaith; Jerome Benveniste; Paolo Cipollini; Bruno Lucas

Abstract: A regional cross-calibration between the first Delay-Doppler altimetry dataset from Cryosat-2 and a retracked Envisat dataset is here presented, in order to test the benefits of the Delay-Doppler processing and to expand the Envisat time series in the coastal ocean. The Indonesian Seas are chosen for the calibration, since the availability of altimetry data in this region is particularly beneficial due to the lack of in-situ measurements and its importance for global ocean circulation. The Envisat data in the region are retracked with the Adaptive Leading Edge Subwaveform (ALES) Retracker, which has been previously validated and applied successfully to coastal sea level research.

The study demonstrates that Cryosat-2 is able to decrease the 1-Hz noise of sea level estimations by $0.3 \mathrm{~cm}$ within $50 \mathrm{~km}$ of the coast, when compared to the ALES-reprocessed Envisat dataset. It also shows that Envisat can be confidently used for detailed oceanographic research after the orbit change of october 2010. Cross-calibration at the crossover points indicates that in the region of study a sea state bias correction equal to 5\% of the significant wave height is an acceptable approximation for Delay-Doppler altimetry.

The analysis of the joint sea level time series reveals the geographic extent of the semiannual signal caused by Kelvin waves during the monsoon transitions, the larger amplitudes of the annual signal due to the Java Coastal Current and the impact of the strong La Niña event of 2010 on rising sea level trends. 


\title{
Cross-calibrating ALES Envisat and CryoSat-2 Delay-Doppler: A coastal altimetry study in the Indonesian Seas
}

\author{
Marcello Passaro \\ Deutsches Geodaetisches Forschungsinstitut der Technischen Universitaet Muenchen \\ (DGFI-TUM, Muenchen, Germany), School of Ocean and Earth Science (University of \\ Southampton, UK) and ESA ESRIN (Frascati, Italy), marcello.passaro@tum.de
} Salvatore Dinardo ${ }^{1}$, Graham D. Quartly ${ }^{2}$, Helen M. Snaith ${ }^{3}$, Jérôme Benveniste ${ }^{4}$, Paolo Cipollini ${ }^{5}$, Bruno Lucas ${ }^{6}$

\begin{abstract}
A regional cross-calibration between the first Delay-Doppler altimetry dataset from Cryosat-2 and a retracked Envisat dataset is here presented, in order to test the benefits of the Delay-Doppler processing and to expand the Envisat time series in the coastal ocean. The Indonesian Seas are chosen for the calibration, since the availability of altimetry data in this region is particularly beneficial due to the lack of in-situ measurements and its importance for global ocean circulation. The Envisat data in the region are retracked with the Adaptive Leading Edge Subwaveform (ALES) Retracker, which has been previously validated and applied successfully to coastal sea level research.

The study demonstrates that CryoSat-2 is able to decrease the $1-\mathrm{Hz}$ noise of sea level estimations by $0.3 \mathrm{~cm}$ within $50 \mathrm{~km}$ of the coast, when compared to the ALES-reprocessed Envisat dataset. It also shows that Envisat can be confidently used for detailed oceanographic research after the orbit change of October 2010. Cross-calibration at the crossover points indicates that in the region of study a sea state bias correction equal to $5 \%$ of the significant wave height is an acceptable approximation for Delay-Doppler altimetry.

The analysis of the joint sea level time series reveals the geographic extent of the semiannual signal caused by Kelvin waves during the monsoon transitions, the larger amplitudes of the annual signal due to the Java Coastal Current and the impact of the strong La Niña event of 2010 on rising sea level trends.
\end{abstract}

Keywords: Coastal Altimetry; ALES; SAR altimetry; Indonesia; sea state bias;

\footnotetext{
${ }^{1}$ Serco/ESRIN, European Space Agency, Frascati, Italy

${ }^{2}$ Plymouth Marine Laboratory, U.K.

${ }^{3}$ British Oceanographic Data Centre, Southampton, U.K.

${ }^{4}$ European Space Research Institute (ESRIN), European Space Agency, Frascati, Italy

${ }^{5}$ Marine Physics and Ocean Climate Research Group, National Oceanography Centre, European Way, SO14 3ZH, Southampton, U.K.

${ }^{6}$ Deimos/ESRIN, European Space Agency, Frascati, Italy
} 
CryoSat-2; Envisat; SARvatore; sea level;

\section{Introduction}

For more than 20 years, studies of sea level and ocean topography have strongly relied on satellite altimetry. Standard altimeters work with a simple radar principle: signals are sent to the sea surface and the reflected echoes are registered onboard in time series called "waveforms". The pulse repetition frequency (PRF) of these altimeters is set in order to guarantee that the noise of consecutive echoes is uncorrelated (Walsh, 1982). This allows their incoherent processing: waveforms are averaged in order to decrease the noise level. Subsequently, a model is fitted to the averaged waveform (a process called "retracking") and the range (the distance between the satellite and the sea surface) is estimated.

Standard altimeters achieve an accuracy of roughly 2-3 $\mathrm{cm}$ for $1-\mathrm{Hz}$ averages (1 measurement every $\sim 7 \mathrm{~km}$ ) (Bonnefond et al., 2011). Despite the remarkable performance, data in the coastal zone are often disregarded due to land and calm water interference in the satellite footprint $(7.3 \mathrm{~km}$ for Envisat and $8.3 \mathrm{~km}$ for Jason for calm seas (Quartly, 1998)) and degraded geophysical corrections. The effort of various research groups has led to a marked improvement in the retrieval of coastal sea level (Vignudelli et al., 2011). Among different coastal-dedicated retracking techniques, the Adaptive Leading Edge Subwaveform (ALES) algorithm was validated on 3 different missions against in-situ data, proving the possibility of applying the same method to both open-ocean and coastal data without degrading the precision when compared to the standard products available (Passaro et al., 2014, 2015b).

In order to improve the noise performance and reduce the footprint, the concept of Delay-Doppler processing (also called "SAR" processing) has been recently applied to radar altimetry. A Delay-Doppler altimeter is used on the CryoSat-2 (CS-2) mission and will be used on Sentinel-3. It sends pulses with a high PRF in order to achieve pulse-to-pulse coherence. Each resolution cell in the along-track direction is characterised by a Doppler frequency that can be exploited using the phase information of the complex echoes that return to the satellite. In this way, a higher number of independent looks can be referred to a reduced footprint (pulse-Doppler limited footprint), which is effectively beam-limited ( $200 \mathrm{~m}$ in the along-track direction) when compared to the classic pulse-limited shape of the standard footprint (Raney, 1998). CS-2 SAR ocean data have been locally validated against in-situ data and model data in the German Bight, showing improvements in precision compared to the same data acquired with the pseudo low-resolution mode (PLRM) (FenoglioMarc et al., 2015).

Both the ALES reprocessing of standard altimetry missions and the new SAR altimetry data should improve the sea level analysis in areas where satellite altimetry has been previously disregarded. A previous study in the North Sea/Baltic Sea intersection zone, an area that is well-sampled by tide gauges, has shown that the ALES-based Envisat dataset has increased the amount and the quality of sea level retrievals compared to other altimetry datasets, allowing a more accurate estimation of the annual cycle up to the coast (Passaro et al., 2015a). The use of CS-2 data 
(starting from 2010) should allow the extension of the Envisat time series (which stopped in April 2012) in order to obtain a dense sampling of the ocean, more suitable for regional analysis, when compared to the Jason series, whose ground track spacing at the equator is $315 \mathrm{~km}$ ( $7.5 \mathrm{~km}$ for CS-2, $90 \mathrm{~km}$ for Envisat).

The aim of this paper is to inter-compare ALES-reprocessed Envisat and CS-2 SAR sea level anomalies in the coastal ocean to: assess the performance of the SAR altimetry data; cross-calibrate the two missions to create multi-mission time-series and test the suitability of the dataset for sea level analysis on a basin-scale.

The analysis is performed in the Indonesian Seas, an area that suffers from the lack of in-situ data despite being of key importance for climate dynamics and a hotspot for sea level rise. Despite the SAR data collection mode not being applied everywhere for CS-2, part of this area of study is included in a so called "SAR box". The two missions are inter-calibrated by means of crossover analysis. Compared to the usual analysis of altimetric time series, this experiment is particularly challenging because of the orbit differences between the two satellites: Envisat had a 35-day repeat cycle, while CS-2 passes over the same ground-tracks once every 369 days, with 30-day sub-cycles.

\section{Area of study}

The Indonesian Seas act as a connection between the western Pacific Ocean and the eastern Indian Ocean (figure 1) and as a key feature of the global ocean circulation: Their straits and passages form the Indonesian throughflow, which transports north Pacific waters into the Indian Ocean.

These waters enter the Indonesian throughflow primarily through the Makassar Strait (figure 2). Flowing south, the mass of water splits with one branch entering the Indian Ocean through the Lombok Strait and another flowing eastward through the Flores Sea and then through the Banda Sea, which has several narrow pathways that lead the water into the Indian Ocean (Gordon, 2005).

The interannual variability of the sea level anomalies in the area is dominated by the El Niño Southern Oscillation. The annual cycle is driven by the monsoon winds, which blow from the west from November to March (northwest monsoon), and from the east from May to September (southeast monsoon).

Rainfall increases over the whole area during the northwest monsoon. In the Java Sea, characterised by shallow depths, the northwest monsoon pushes low-salinity water from the South China Sea up to the southern Makassar Strait, while highsalinity water from the Pacific Ocean enters the basin during the southeast monsoon (Durand and Petit, 2011). The reversal of the monsoon winds also inverts the direction of the Java Coastal Current, which follows the bathymetry slope south of the island of Java (Syamsudin and Kaneko, 2013).

Several studies have pointed out how the sea level in the south-east Asian region is rising at rates higher than the global mean. In their study based on reconstruction techniques to extend the altimetry analysis in time, Strassburg et al. (2014) have argued that the fast-rising sea level trends of the last two decades in the area may not be the norm and could decrease with a weakening of the trade winds related to the phase of the Pacific Decadal Oscillation. This study and Palanisamy et al. 


\begin{tabular}{|l|c|c|c|}
\hline & $0-50 \mathrm{~km}$ & $50-100 \mathrm{~km}$ & $100-150 \mathrm{~km}$ \\
\hline \hline North Java & $24 \mathrm{~m}$ & $40 \mathrm{~m}$ & $46 \mathrm{~m}$ \\
South Java & $757 \mathrm{~m}$ & $2623 \mathrm{~m}$ & $3397 \mathrm{~m}$ \\
\hline \hline
\end{tabular}

Table 1: Mean depth in relation to the distance from the coast in North Java and South Java.

(2015) found that trends increase from west to east in the geographical domain. The altimetry data which these studies rely on are gridded and interpolated, while our analysis is based on along-track data averaged according to the distance from the coast. Results based on the interpolation of altimetry data that are not optimised for the coastal zone may cause gaps and lower quality of the measurements. At the same time, given the highly populated coastal areas, it is beneficial to improve the quality of altimetry data in order to understand the dynamics of the sea level close to the coast and on smaller scales.

The use of local tide gauge sea level records is prevented by discontinuities and the instability of the reference level due to strong vertical land movements, as shown by Fenoglio-Marc et al. (2012). The availability of long and reliable satellite altimetry records could therefore help overcome the lack of in-situ data.

Figure 1 shows the geographical limit of CS-2 SAR data and defines two domains that were selected North and South of Java Island (NJ and SJ from now on). Table 1 shows the mean depth of NJ and SJ in relation to the distance from the coast, which is used as a criterion in the analysis of the next sections. The domains were chosen in order to contain both data from Envisat and from CS-2 SAR and to be representative of two very different conditions of a coastal ocean environment: in SJ, a strong coastal current with pronounced bathymetry slope characterised by moderate waves and variability; in NJ, a shallow area with calmer sea state. In the crossover analysis (section 4.2) all the CS-2 SAR measurements included in the latitude box of the map are taken into account.

In section 4.3, time series of averaged cross-calibrated sea level measurements are generated for the Java Sea, Flores Sea, Banda Sea, Bali Sea and Ceram Sea, defined according to the Limits of Ocean and Seas published by the International Hydrographic Organization in 1953 (see figure 2), despite the limited geographical availability of CS-2 SAR data. Figure 2 shows the extent of each of the Indonesian Seas. 


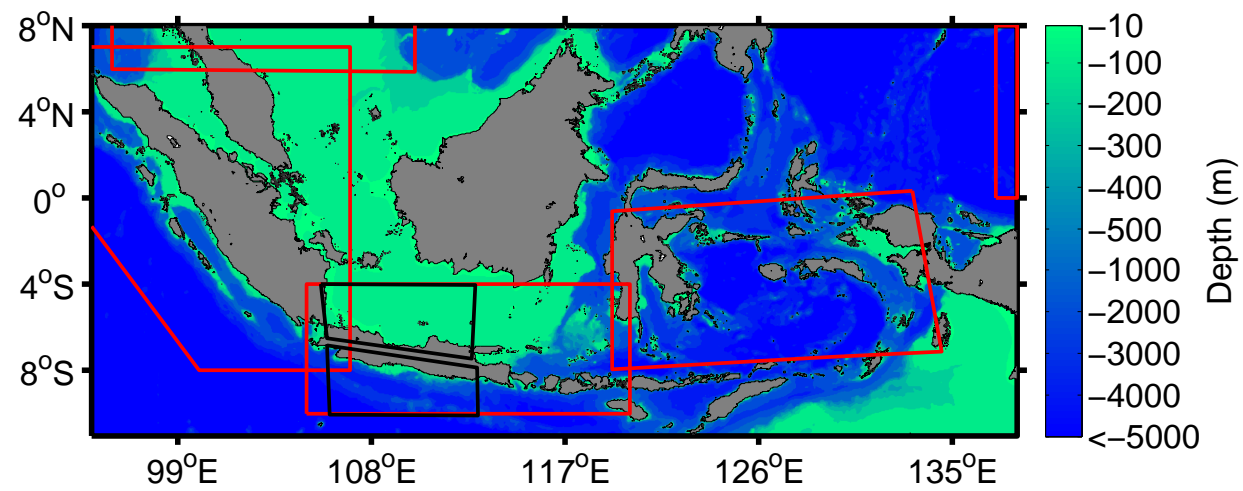

Figure 1: The domains selected North and South of Java Island (NJ and SJ) delimited by the black lines and the SAR boxes of CS-2 (delimited by the red lines).

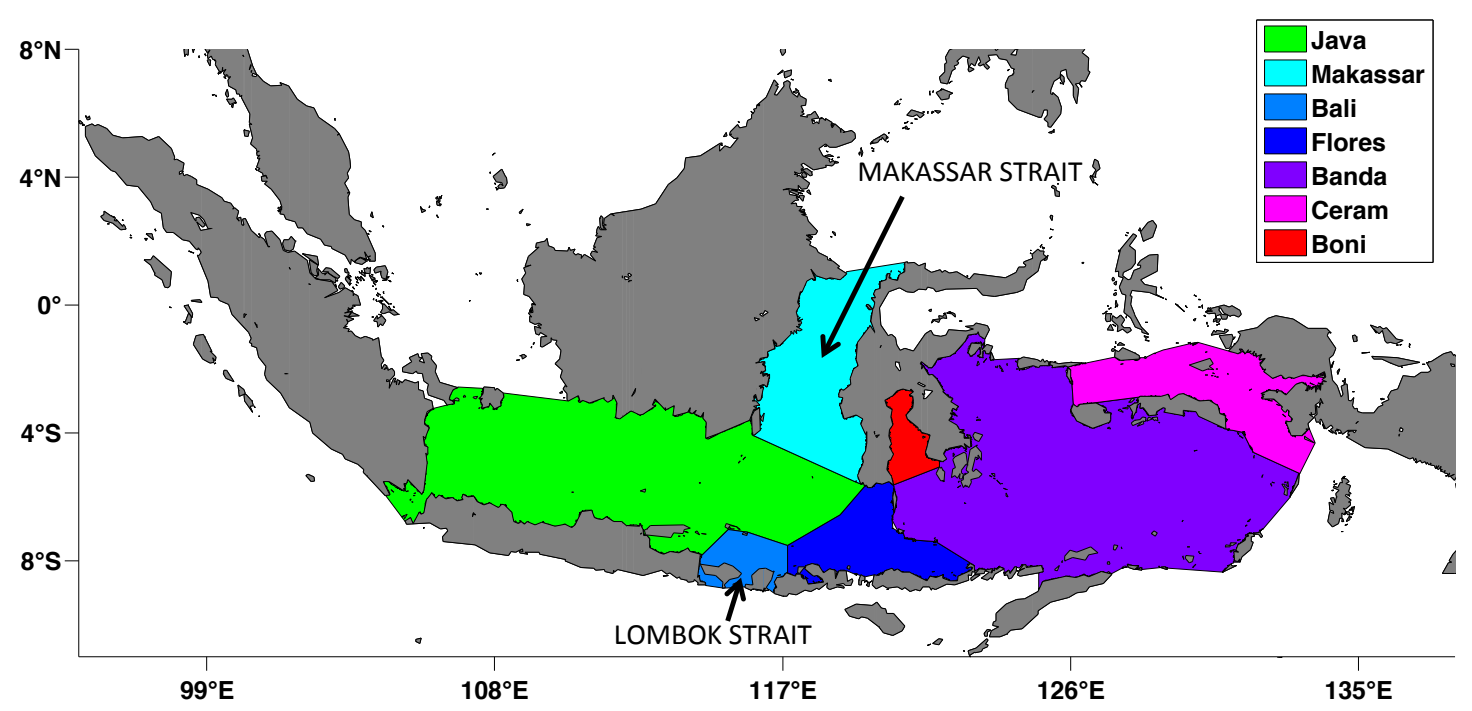

Figure 2: The basins of interest within the Indonesian Seas, defined according to the Limits of Ocean and Seas published by the International Hydrographic Organization in 1953.

\section{Data and Methods}

\subsection{Altimetry Dataset}

This study uses altimetry data from Envisat reprocessed with ALES and from CS-2 SAR mode distributed with the ESA SAR Versatile Altimetric Toolkit for Ocean and land Research and Exploitation (SARvatore) service. Envisat data cover orbital Phase B (from autumn 2002 to the 22nd October 2010) and orbital Phase C (from 23rd October 2010 to 8th April 2012, after which contact with the satellite was lost). During Phase C, Envisat was in an orbit $17.4 \mathrm{~km}$ lower than in Phase B, resulting in a slightly shorter repeat cycle of 30 days, and the overflight of different 
ground tracks. In this paper, when a distinction is needed, the two phases of Envisat will be called Env B (Envisat Phase B) and Env C (Envisat Phase C).

While over the vast majority of the ocean surface CS-2 operates in low resolution mode (LRM), i.e. as a standard pulse-limited altimeter that does not exploit the pulse-to-pulse coherency, "SAR" boxes are planned during the orbit, in particular when the satellite overpasses coastal oceans. Figure 1 shows that only a part of the Indonesian Seas is covered by a SAR box. Given the focus of this research and the content of the SARvatore product, only CS-2 SAR data are used in the analysis. SARvatore data were downloaded from gpod.eo.esa.int in May 2015. SARvatore processes the CS-2 raw data in the SAR boxes using the SAMOSA2 functional form (Ray et al., 2015); the settings suggested for coastal areas are all applied, i.e. Hamming weighting window on the burst data, zero-padding and extended radar receiving window size (for details, see Dinardo and Benveniste (2013)).

In order to harmonise the set of geophysical corrections applied to the range measurement to derive the sea level height, the mean sea surface (MSS) from DTU13, the tidal amplitudes from DTU10 and the ECMWF-forced Dynamic Atmosphere Corrections are applied to both missions (for a justification of the choices, see Passaro et al. (2015a)). Concerning the Wet Tropospheric correction, given that CS-2 does not have a microwave radiometer on board, this study applies the ECMWF-based correction to all the datasets.

Based on what the available literature suggests for pulse-limited altimetry (Andersen and Scharroo, 2011), a tentative sea state bias (SSB) correction (still absent in the SARvatore product at the time of writing) is applied in this study, equal to $4 \%$ of the SWH. An improvement of this tentative value is then proposed in section 4.2 .

\subsection{Data screening and outlier detection}

ALES Envisat 18-Hz sea level measurements were screened using the methodology already described in Passaro et al. (2015a). CS-2 data in SARvatore are distributed as $20-\mathrm{Hz}$ and $1-\mathrm{Hz}$ averages. In this study, $1-\mathrm{Hz}$ points were recomputed starting from $20-\mathrm{Hz}$ estimations using the same methodology as in Envisat, with the following exceptions:

- The Coastal Proximity Parameter (CPP) parameter, which quantifies the influence of land on the radar returned echoes (Cipollini, 2011) and is used in the $18-\mathrm{Hz}$ data screening for Envisat, is not available for CS-2. Given the different footprint and antenna characteristics of CS-2, the Envisat CPP parameter cannot be used;

- The fitting error in SARvatore is computed on the whole waveform and provided in waveform power units. A maximum value of 4 power units in the fitting error is adopted here, considering that analysis on open ocean data has shown that $\sim 99 \%$ of the waveforms are fitted within this threshold (S. Dinardo, personal communication).

The following additional screening was added on the 1-Hz points of both Envisat and CS-2 in order to exclude noisy retrievals, non-representative averages and errors in the corrections. A $1-\mathrm{Hz}$ point was excluded from the analysis if: 
- The number of valid measurements within the $1-\mathrm{Hz}$ block was less than 5 .

- The standard deviation (std) of the valid measurements within the $1-\mathrm{Hz}$ block was larger than $0.20 \mathrm{~m}$; this criterion is justified by the fact that such a high slope in sea level would be not plausible in a distance of $\sim 7 \mathrm{~km}$.

- The sum of the geophysical corrections, excluding ocean tides, was smaller than $1 \mathrm{~m}$; such values would be unrealistic given that, for example, the dry tropospheric correction has a global mean of $2.31 \mathrm{~m}$ with only $2 \mathrm{~cm}$ std (Andersen and Scharroo, 2011).

\subsection{Methods for crossover analysis}

To verify the precision and the agreement between Envisat and CS-2 SAR, a comparison of the sea level at the crossover points was performed. This is a standard practice in altimetry and has been used is several publications as a key indicator of the data quality for altimetric missions (see Labroue et al. (2012) for a comprehensive list of references). In order to reduce the impact of oceanic variability, crossovers are taken into consideration if the time lag between the two passes is shorter than 10 days. For most crossover analyses, coastal areas, shallow seas and high variability areas are generally avoided, while in this research they are explicitly taken into consideration. Crossovers are here defined as all the available 1-Hz points of two crossing tracks that are closer than $5 \mathrm{~km}$. Both Envisat and CS-2 measurements have been referred to the same ellipsoid and the absolute bias found for Envisat (see Bonnefond et al. (2013)) was taken into account. Four crossover cases were considered:

- Envisat Phase B ascending versus Envisat Phase B descending passes (case EnvB-EnvB)

- Envisat Phase C ascending versus Envisat Phase C descending passes (case EnvC-EnvC)

- Envisat Phase C ascending and descending versus CS-2 ascending and descending passes (case EnvC-CS2)

- CS-2 ascending versus CS-2 descending passes (case CS2-CS2)

\subsection{Regional derivation of seasonal signals and trends in the sea level}

Data were grouped depending on the corresponding basin and averaged every month. Given the stress in this study on the evaluation of coastal performances, data in NJ and SJ were divided according to distance from the coastline (0-50 km, 50-100 $\mathrm{km}, 100-150 \mathrm{~km})$. Estimations of annual and semiannual cycles were performed using the Prais Winsten Feasible Generalised Least Square Estimator, which accounts for the problem of autocorrelation of the residuals in geophysical time series (Prais and Winsten, 1954). Subsequently, the seasonal cycle was removed from the time series and the trends were estimated using the same method. 


\subsection{Comparison of performances between Envisat and CS-2}

In this section, the test areas of NJ and SJ are used for comparison of the performances of Envisat and CS-2, with particular focus on the coastal zone. The top plots of figure 3 show the number of passes for each month: the number of measurements available in the sub-basins in one month is similar in the time series of both missions. In two months of 2005 many passes of Envisat are missing and this holds also for the initial 3 months after the launch of CS-2. In order to maintain the consistency, for each mission statistics are shown only for months where more than 10 passes are available.

In order to check the consistency of the dataset, the middle plots of figure 3 show the standard deviation of the retrieved SLA within $50 \mathrm{~km}$ of the coast. A single averaged sea level value for each pass of Envisat or CS-2 is assigned and each point on the plot corresponds to the std considering all available passes in that month. The top plots show therefore the variability of the derived sea level (including errors in the corrections) within a month in the domain of interest. The coastal region of SJ has a higher variability than the corresponding area in NJ, as expected. In both regions, the average variability is consistent in all three missions: in SJ there is an average monthly std of $9.2 \mathrm{~cm}$ for Env B, $10.0 \mathrm{~cm}$ for Env C and $9.5 \mathrm{~cm}$ for CS-2; in NJ the values are $7.0 \mathrm{~cm}$ for Env B, $7.8 \mathrm{~cm}$ for Env C and 7.2 for CS-2. In the 15 months when sufficient measurements were available from both Env $\mathrm{C}$ and CS-2, the root mean square difference between the monthly std from Env $\mathrm{C}$ and CS-2 is $2.4 \mathrm{~cm}$ in NJ and $1.8 \mathrm{~cm}$ in SJ. The retrieved variability is therefore very comparable, despite the fact that the two satellites were sampling different areas on different days. In SJ, all the months with a std exceeding $0.15 \mathrm{~m}$ are located in May or in November, i.e. during the expected onset of the monsoons.

Figure 4 shows the monthly average of the 20 (18)-Hz SLA measurement noise computed at each 1-Hz location for CS-2 (Envisat) within $50 \mathrm{~km}$ of the coast. In both NJ and SJ, the average retrieved SWH is plotted in green for each mission. The noise level of Envisat is consistent between Phase B and Phase C. This helps to highlight the differences between the sea state of the two areas and the relationship between measurement noise and sea state, since higher SWH corresponds to noisier data in all the datasets.

A significant improvement in precision, when compared to Envisat, is remarkable in CS-2, whose noise is up to $1 \mathrm{~cm}$ lower than for Env $\mathrm{C}$ in the same months for both NJ and SJ. This result confirms that SAR altimetry is intrinsically more precise than the standard processing. Although the validation of CS-2 SWH estimation is not an objective of this research, it is remarkable that in both the areas CS-2 SWH is on average in very good agreement with the SWH measured by Env C.

Figure 3 also shows the variability of the geophysical corrections, i.e. the sum of wet (WTC) and dry tropospheric correction (DTC), dynamic atmosphere correction (DAC), ionospheric correction and sea state bias. Envisat and CS-2 data use the same dataset for WTC, DTC and DAC. The std of the corrections applied to CS-2 is almost double than that of Envisat. This difference is explained by considering the orbit of the satellites. Envisat follows a sun-synchronous orbit, therefore the satellite 

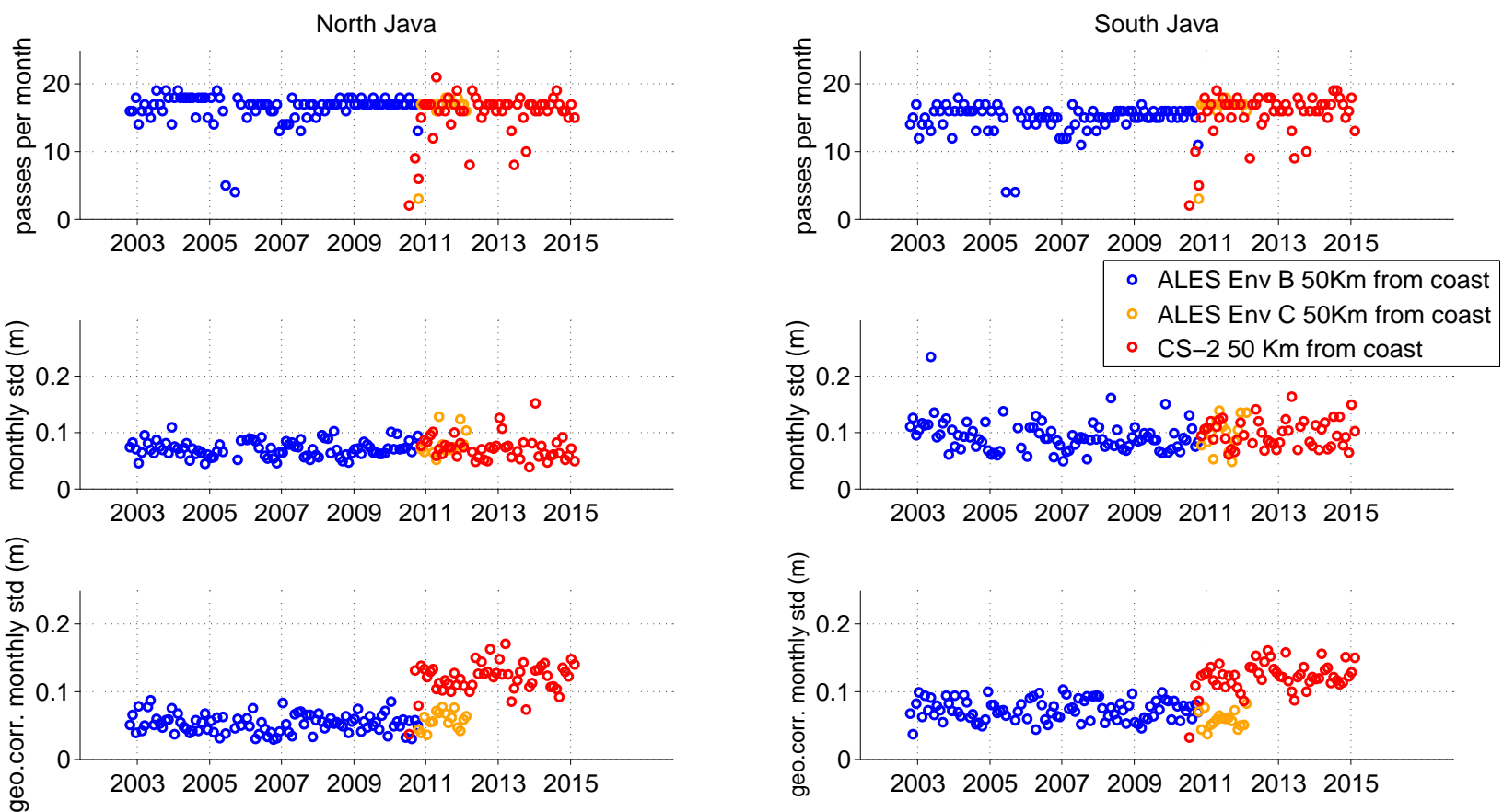

Figure 3: Top: number of satellite passes available in each month. Middle: Standard Deviation of the monthly SLA values in SJ and NJ within $50 \mathrm{~km}$ of the coast for Env B ALES (blue), Env C ALES (orange) and CryoSat-2 SARvatore (red). Only data from months when at least 10 passes were available are shown. Bottom: Standard Deviation of the monthly geophysical correction applied to the SLA estimations.

flies over the same area at the same time of day. This is not true for CS-2, as it is shown in figure 5: depending on ascending and descending orbits, Envisat overpasses the area in two clearly defined sections of the day, while the measurements of CS-2 span the whole 24 hours. In fact, all the geophysical effects have their own diurnal cycle linked to the daily variation of the atmospheric pressure (Ponte and Ray, 2002), ionospheric electron content (Liu et al., 2011) and wet and dry component in the troposphere (Jin et al., 2009).

Tables 2 and 3 show the consistency of noise and variability w.r.t. the distance from the coast in NJ and SJ, by averaging in time the previous statistics. In both NJ and SJ, the difference in variability between the different missions is always less than $1.5 \mathrm{~cm}$. This is particularly important considering that both Env C and CS-2 sample areas that were not sampled by previous missions, whose data are used to build the MSS models.

Compared to figure 4 , the noise in the tables is scaled at $1 \mathrm{~Hz}$ level, i.e. the highrate noise is divided by the root mean square of the number of measurements in each $1 \mathrm{~Hz}$ block. The data confirm the robustness of the improvement in precision brought by CS-2, quantifiable as roughly $0.3 \mathrm{~cm}$ at $1 \mathrm{~Hz}$ level w.r.t. Envisat regardless of the sea state. 


\begin{tabular}{|c|c|c|c|c|}
\hline NORTH JAVA & Alt data set & $0-50 \mathrm{~km}$ & $50-100 \mathrm{~km}$ & $100-150 \mathrm{~km}$ \\
\hline \hline \multirow{3}{*}{ Monthly std } & ALES Env B & $7.1 \mathrm{~cm}$ & $7.2 \mathrm{~cm}$ & $6.4 \mathrm{~cm}$ \\
\cline { 2 - 5 } & ALES Env C & $7.8 \mathrm{~cm}$ & $7.4 \mathrm{~cm}$ & $7.7 \mathrm{~cm}$ \\
\cline { 2 - 5 } & CS-2 & $7.2 \mathrm{~cm}$ & $6.9 \mathrm{~cm}$ & $6.6 \mathrm{~cm}$ \\
\hline \hline \multirow{3}{*}{$1-\mathrm{Hz}$ noise } & ALES Env B & $1.2 \mathrm{~cm}$ & $1.1 \mathrm{~cm}$ & $1.2 \mathrm{~cm}$ \\
\cline { 2 - 5 } & ALES Env C & $1.2 \mathrm{~cm}$ & $1.2 \mathrm{~cm}$ & $1.2 \mathrm{~cm}$ \\
\cline { 2 - 5 } & CS-2 & $0.9 \mathrm{~cm}$ & $0.8 \mathrm{~cm}$ & $0.8 \mathrm{~cm}$ \\
\hline \hline
\end{tabular}

Table 2: Variability of the parameters of interest (standard deviation of the monthly SLA values and average $1-\mathrm{Hz}$ noise of the SLA values) in North Java depending on the distance from the coastline for Env B ALES, Env C ALES and CS-2 SARvatore.

\begin{tabular}{|c|c|c|c|c|}
\hline SOUTH JAVA & Alt data set & $0-50 \mathrm{~km}$ & $50-100 \mathrm{~km}$ & $100-150 \mathrm{~km}$ \\
\hline \hline \multirow{3}{*}{ Monthly std } & ALES Env B & $9.2 \mathrm{~cm}$ & $8.0 \mathrm{~cm}$ & $7.8 \mathrm{~cm}$ \\
\cline { 2 - 5 } & ALES Env C & $10.0 \mathrm{~cm}$ & $9.5 \mathrm{~cm}$ & $9.0 \mathrm{~cm}$ \\
\cline { 2 - 5 } & CS-2 & $9.5 \mathrm{~cm}$ & $8.2 \mathrm{~cm}$ & $8.7 \mathrm{~cm}$ \\
\hline \hline \multirow{3}{*}{$1-\mathrm{Hz}$ noise } & ALES Env B & $1.7 \mathrm{~cm}$ & $1.6 \mathrm{~cm}$ & $1.6 \mathrm{~cm}$ \\
\cline { 2 - 5 } & ALES Env C & $1.7 \mathrm{~cm}$ & $1.6 \mathrm{~cm}$ & $1.6 \mathrm{~cm}$ \\
\cline { 2 - 6 } & CS-2 & $1.4 \mathrm{~cm}$ & $1.3 \mathrm{~cm}$ & $1.3 \mathrm{~cm}$ \\
\hline \hline
\end{tabular}

Table 3: Variability of the parameters of interest (standard deviation of the monthly SLA values and average $1-\mathrm{Hz}$ noise of the SLA values) in South Java depending on the distance from the coastline for Env B ALES, Env C ALES and CS-2 SARvatore. 

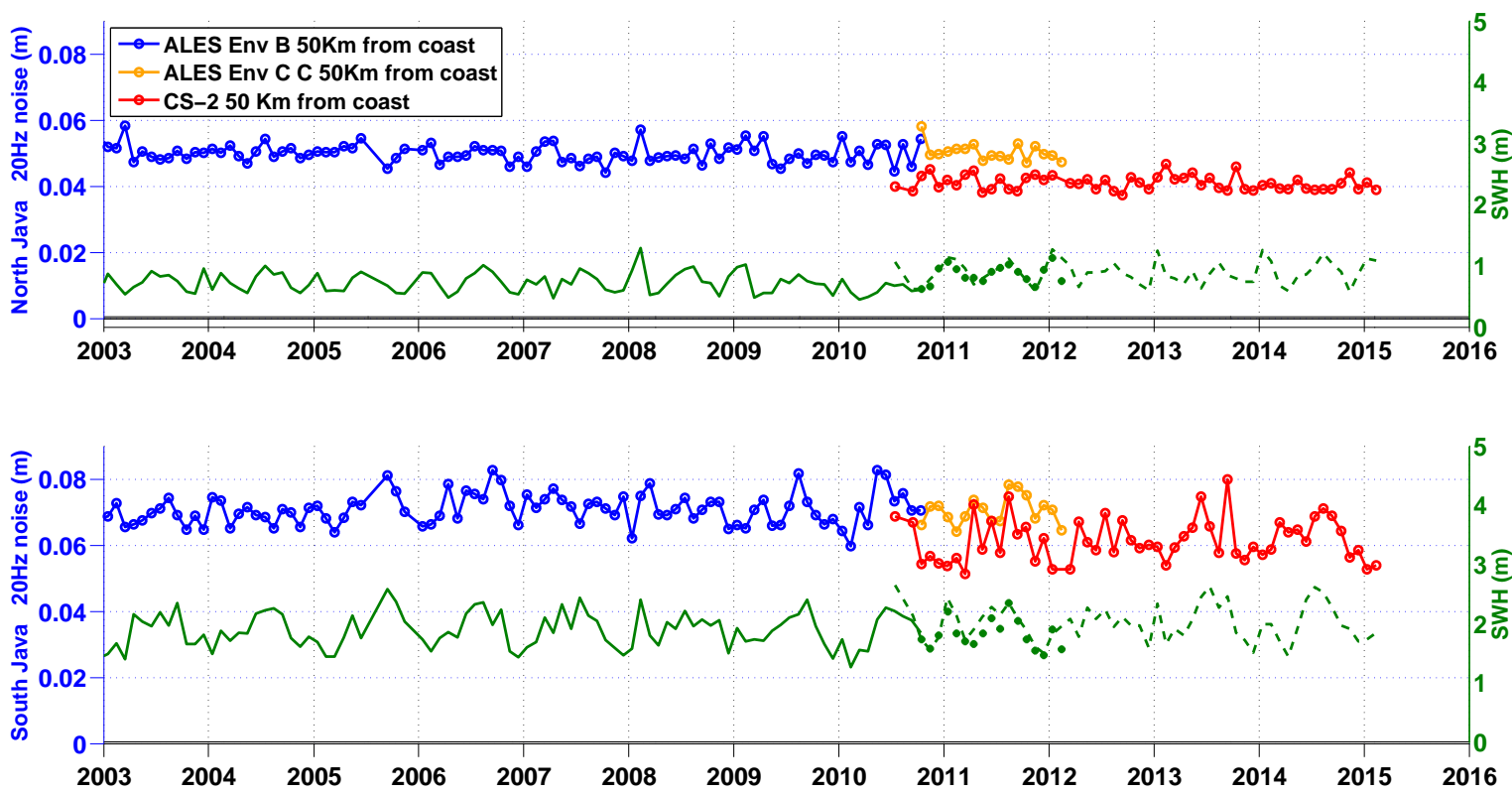

Figure 4: Average $20 \mathrm{~Hz}$ noise of the SLA values in SJ and NJ within $50 \mathrm{~km}$ of the coast for Env B ALES (blue), Env C ALES (orange) and CS-2 SARvatore (red). Also shown is the average estimated Significant Wave Height for each mission (green curves)

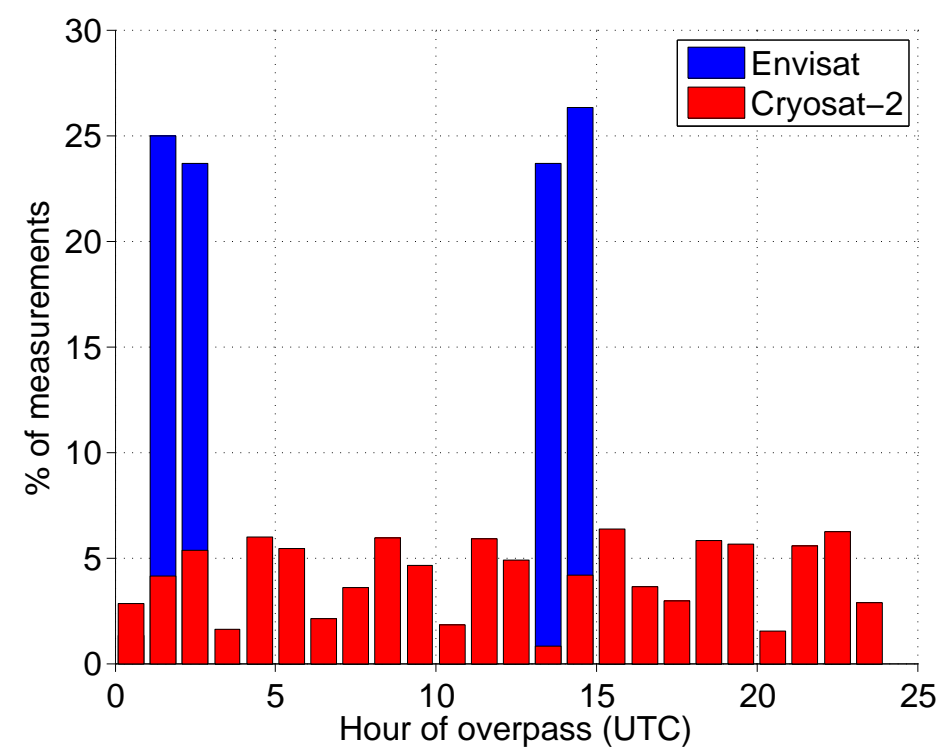

Figure 5: Overpass time in the Java region for Envisat (blue) and CryoSat-2 (red).

\subsection{Crossover analysis and cross-calibration}

In this section, the analysis of the crossovers in the test areas of NJ and SJ is discussed, in order to cross-calibrate the two missions. Figure 6 shows the charac- 
teristics of the crossovers for each case in terms of time lag and distance from the coast. While crossovers in case EnvC-CS2 span the whole 10 days of permitted time difference, all the other cases, due to the orbit characteristics, are bounded to specific time lags that are latitude dependant. In terms of distance from the coastline, valid case CS2-CS2 crossovers were found only further than $70 \mathrm{~km}$ from the coast, while all the other cases were representative of both coastal and open ocean conditions.

Whilst the mono-mission crossovers lie in discrete latitudinal bands $\left(\sim 9.8^{\circ} \mathrm{S}\right.$ for $\mathrm{CS} 2-\mathrm{CS} 2,9.8^{\circ}, 8.2^{\circ} \& 4.8^{\circ} \mathrm{S}$ for EnvB-EnvB, and 8.6 \& $6.7^{\circ} \mathrm{S}$ for EnvC-EnvC), the EnvC-CS2 crossovers occur at all latitudes (not shown), corresponding to the full range of distances from the coast and the full range of time separations. This also means that the phase difference of any error in a component of the tide model is fairly evenly spread over $[0,2 \pi]$ and thus tidal uncertainties will produce no mean offset between the two SLA datasets.
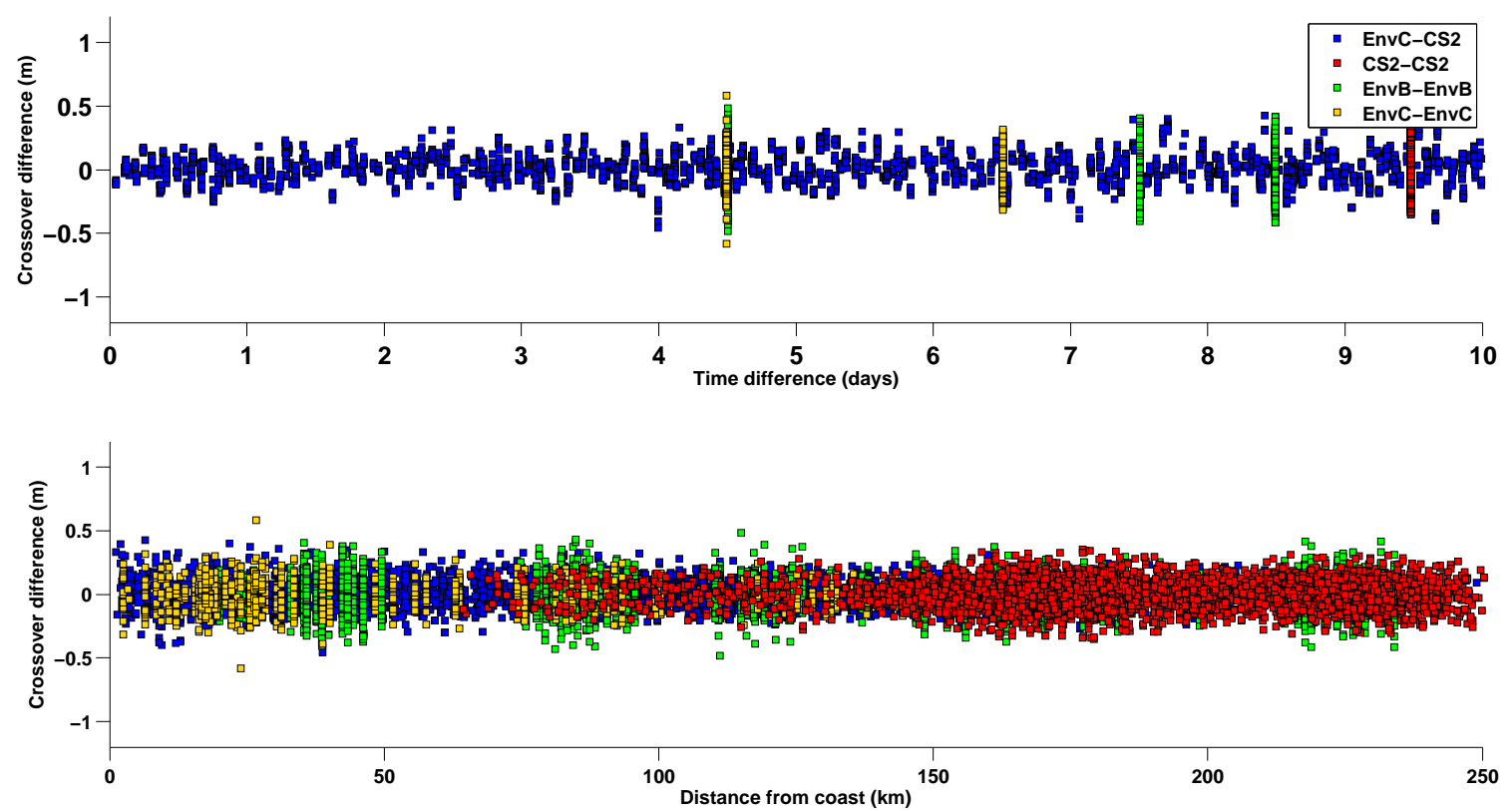

Figure 6: Upper plot: distribution of crossover differences depending on time difference between the satellite passes. Lower plot: distribution of crossover differences depending on distance from the coastline.

In order to have a fair comparison, the histogram on the left of figure 7 compares the four cases considering only points located further than $70 \mathrm{~km}$ from the coast. Performances for different missions are extremely similar and unbiased, since the mean of the crossover differences is zero. Concerning mono-mission crossovers, the small differences in the histogram of case CS2-CS2 compared to EnvB-EnvB and EnvC-EnvC correspond to the time differences of the crossovers seen in figure 6 . Concerning the case EnvC-CS2, the crossover differences have a mean of $1.4 \mathrm{~cm}$, which goes down to $-0.6 \mathrm{~cm}$ when considering the crossover differences without applying any SSB correction to either of the two missions (black histogram in the 
plot on the right). The mean of the crossover differences is considerably lower than the global mean difference found by (Labroue et al., 2012) between Env B and CS-2 LRM mode crossovers $(5.8 \mathrm{~cm})$, which considered only one month of data and only deep water and low variability region.
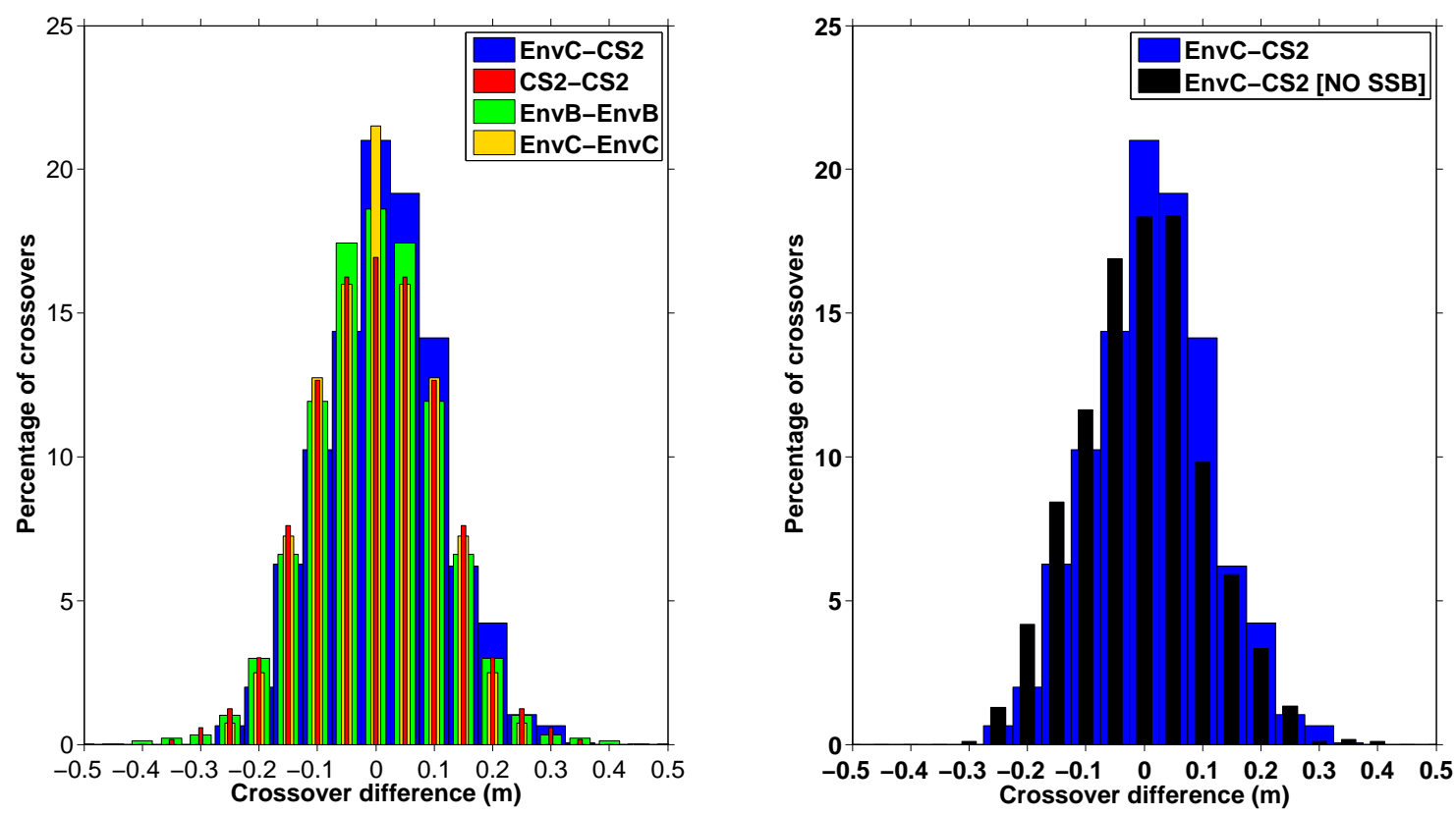

Figure 7: Left: Histogram of crossover differences considering only points farther than $70 \mathrm{~km}$ of the coast. Right: Same histogram with focus on the crossovers between Env C and CS-2 with and without applying a SSB correction to each dataset.

A clearer evaluation that considers both coastal and open ocean conditions is found in figure 8 . The plots focus on the coastal zone, showing the statistics between 0 and $25 \mathrm{~km}$ and between 25 and $50 \mathrm{~km}$ from the coast, considering as "open ocean" anything beyond $50 \mathrm{~km}$. Statistics for the case CS2-CS2 in the coastal zone are not presented due to the lack of coastal crossovers in the area of study for CS-2. The upper plot shows the mean of the crossover differences. The cases of the same mission are centred on zero within half a $\mathrm{cm}$. The EnvC-CS2 comparison shows a bias slightly higher than $1 \mathrm{~cm}$ in the area closest to the coast and in the open ocean. The standard deviation of the crossover differences is about $10 \mathrm{~cm}$ for all cases in the open ocean; it increases in the coastal zone, but is always less than $15 \mathrm{~cm}$ (figure 8 , middle plot).

An analysis of the SLA differences at the EnvC-CS2 crossovers w.r.t. the SWH estimated by CS-2 is shown in figure 9 for NJ and SJ. The difference of wave conditions encountered in the two test regions is immediately visible: NJ never encounters a SWH higher than $2 \mathrm{~m}$ in the observed period, while in SJ most of the retrieved SWH values are above $1.5 \mathrm{~m}$. The linear fitting gives the following relationship:

$$
(\text { EnvC-CS2 })=-0.002+0.010 \times \mathrm{SWH}
$$



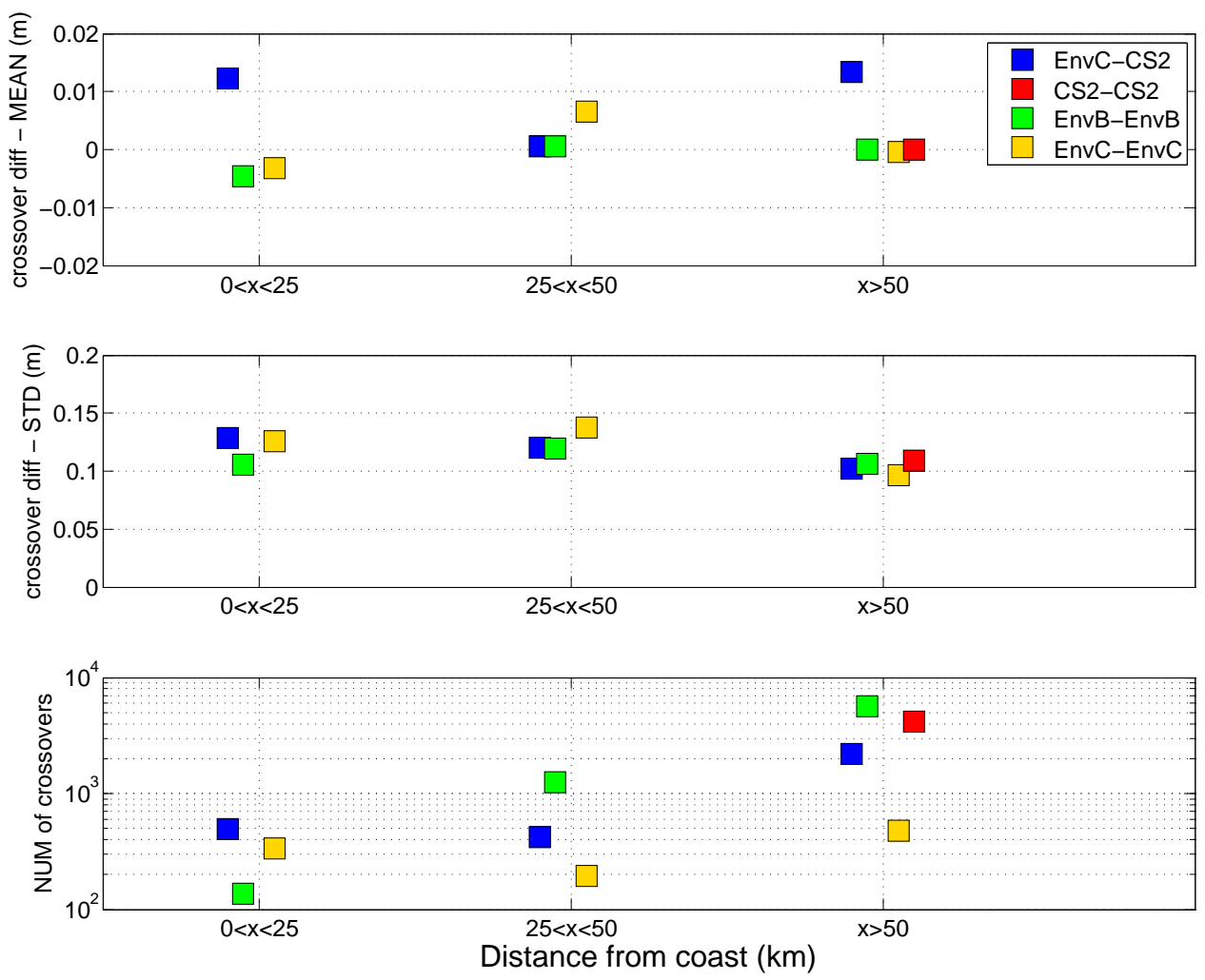

Figure 8: Mean (top), standard deviation (middle) and number (bottom) of crossover differences grouped according to the distance from the coast. The squares are horizontally displaced to facilitate the display.

This relationship is therefore used to cross-calibrate the CS-2 SSHA estimations and a "bias-corrected" version of the dataset is produced. The SWH coefficient in Eq. 1 is equivalent to adding another $1 \%$ to the SSB correction. It is therefore concluded that an overall regionally unbiased cross-calibration between Envisat and CS-2 is achievable by approximating the SSB correction for SAR altimetry at $5 \%$ of the SWH, rather than the $4 \%$ originally recommended.

In order to test the validity of the cross-calibration across the test area, figure 10 shows the same statistics as figure 8 only for EnvC-CS2 case, separating the results according to the distance from the coast and the sub-basin of reference. Despite the overall unbiased statistics shown previously, small regional mean biases are still present, although they do not exceed $2 \mathrm{~cm}$. The top plot shows the mean differences at crossovers without applying a SSB correction for any of the two datasets: also in this case, local biases are of the same order of magnitude.

Both figure 8 and figure 10 show that all the crossover statistics have a higher std within $50 \mathrm{~km}$ of the coast compared to the values offshore. This additional difference of 1 to $4 \mathrm{~cm}$ could be attributed to the residual tidal variability that is left in the signal, because tidal models are less precise in coastal zones and in areas with complicated topography. Stammer et al. (2013) evaluated the DTU10 tidal model 


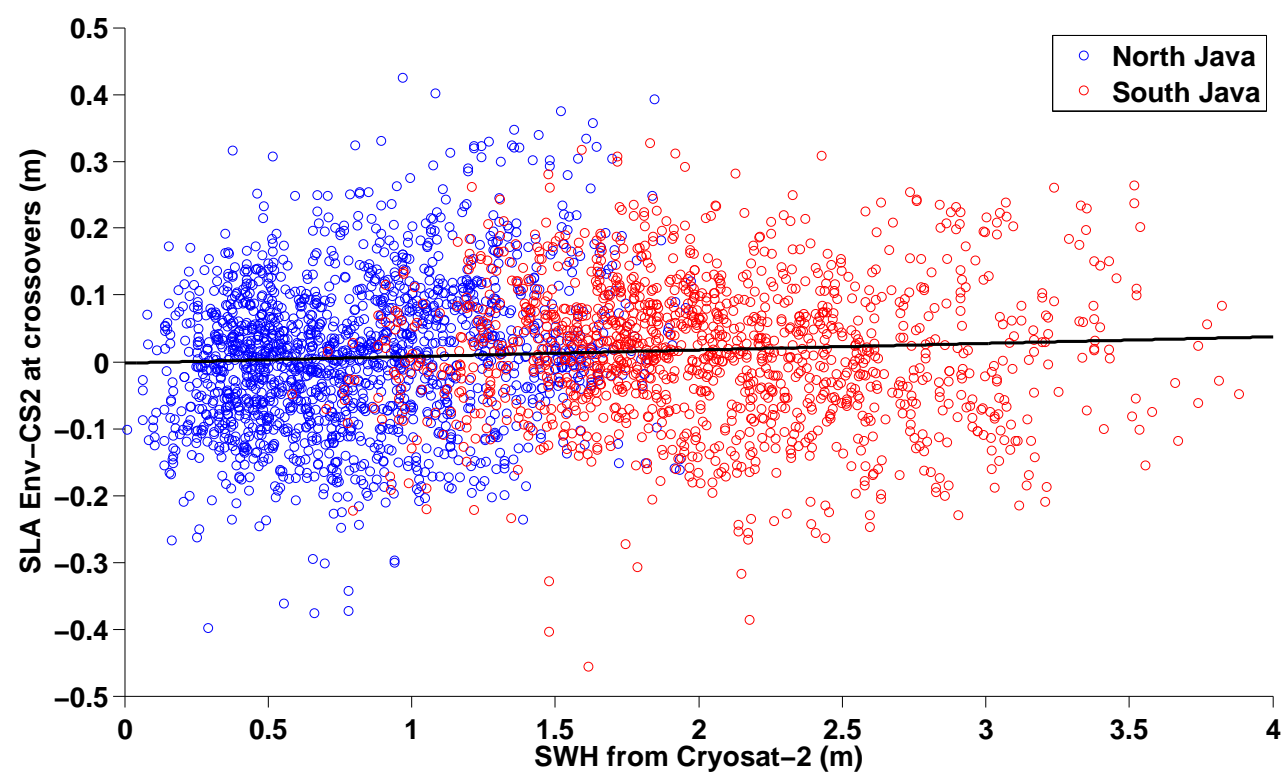

Figure 9: SLA difference at crossover points versus SWH estimation from CryoSat-2; the linear fitting shows a slope of $1 \mathrm{~cm}$ in $1 \mathrm{~m}$ and an intercept at $-2 \mathrm{~mm}$.

against shelf water tide stations and estimated a cumulative error of $5.4 \mathrm{~cm}$ (with M2 and S2 components having the largest differences), which decreases to $1.1 \mathrm{~cm}$ in the open ocean. By computing the std of 7 tidal models including DTU10, the largest uncertainties in our area of study were found for the M2 constituent very close to the coast (up to $3 \mathrm{~cm}$ ), decreasing to $0-1 \mathrm{~cm}$ further offshore (figure 1 of the same paper). The uncertainty was found to be higher in the internal Indonesian Seas, which is in agreement with the higher std of the coastal crossovers found in NJ compared to SJ.

In SJ, the higher coastal std at the crossovers could be also attributed to anomalies of the Java Coastal Current, whose variability may have timescales shorter than 10 days. High-resolution modelling studies have suggested that the intra-seasonal variability has a time scale of 30-60 days (e.g. Iskandar et al. $(2006,2014))$ and the only known mooring data in this region shows deep fluctuations in this current to last at least a couple of weeks (see Figs. 2b-d of Sprintall et al. (1999)). Therefore it is a reasonable assumption that SLA variations are not large within a typical 10-day interval.

Considering these results, it is important to stress that the SSB correction for Envisat is based on a parametric model that takes into account also the wind information derived from the backscatter coefficient estimated by the altimetric measurements (Andersen and Scharroo, 2011) and that the SSB field is not yet being recomputed using ALES estimations. At the same time, the coefficients of a parametric SSB model can be mission-dependent and even the validity of this model has yet to be demonstrated for the SAR-altimetry observing principle. Future studies should address this issue, but for the present research it is found that the derived SSB correction equal to $5 \%$ of the SWH is an acceptable value and does not add 
further biases in the cross-calibration of the two missions being considered.
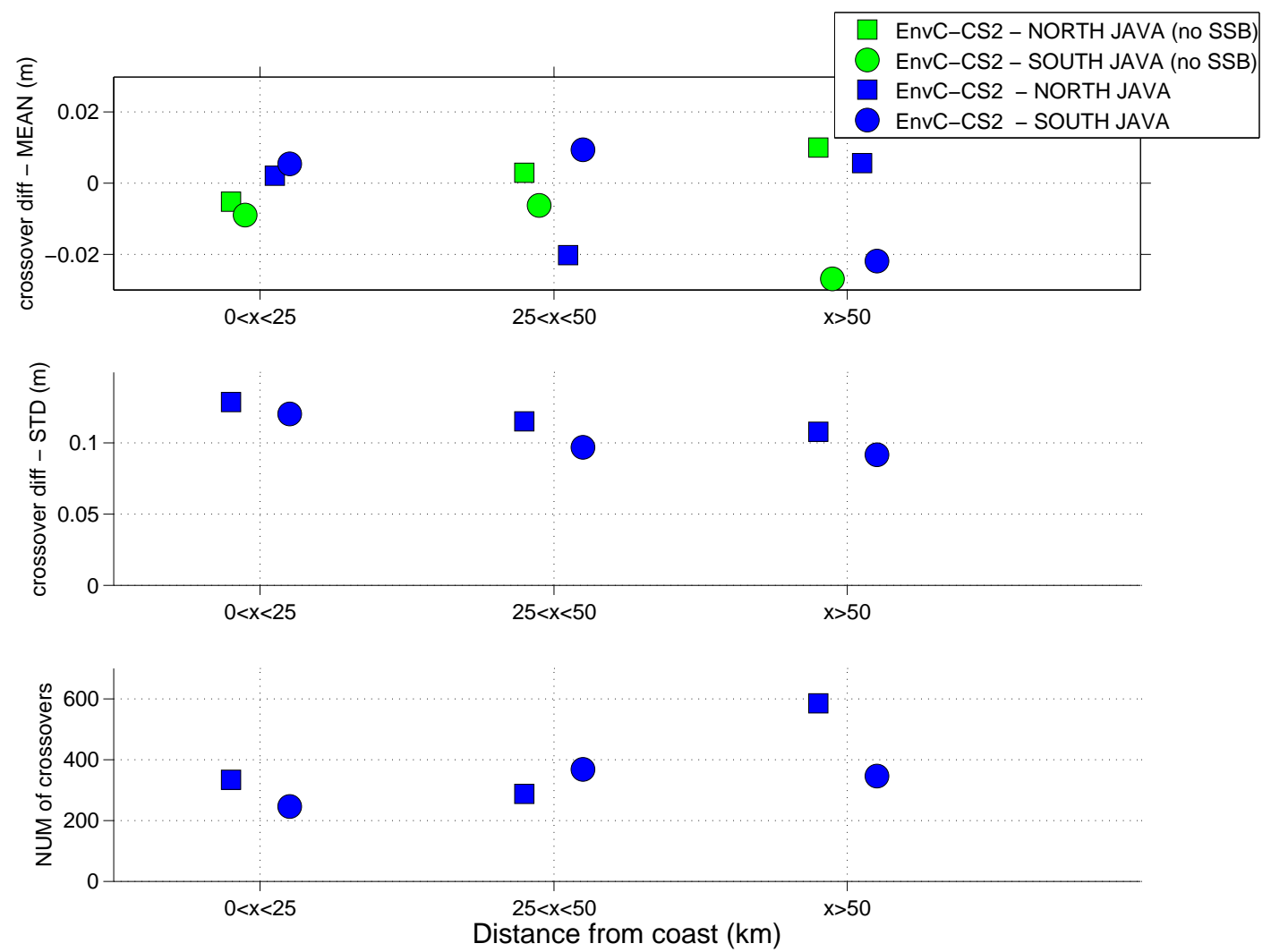

Figure 10: Mean (top), standard deviation (middle) and number (bottom) of crossover differences grouped according to the distance from the coast and subbasin of reference. The symbols are horizontally displaced to facilitate the display. The green symbols refer to the case in which the SSB correction is not applied to either of the dataset.

\subsection{Inter-calibrated time series}

This section analyses the inter-calibrated multi-mission sea level time series. In the first part, the sea level variability of NJ and SJ is analysed in terms of distance from the coast and different datasets. Subsequently, the results for the different Indonesian Seas are presented and discussed.

\subsubsection{North Java and South Java}

The variability of the sea level is here analysed for NJ and SJ in terms of trend, annual cycle amplitude and semiannual cycle amplitude. Statistics are computed for different distances from the coast $(0-50 \mathrm{~km}, 50-100$ and $100-150 \mathrm{~km})$ and time series are formed using data from:

- Envisat Phase B (Env B)

- Envisat Phase B and Envisat Phase C (Env B+C) 
- Envisat Phase B and CS-2 up to the end of Envisat Phase C availability (Env $\mathrm{B}+\mathrm{CS} 2 \mathrm{lim})$

- Envisat Phase B and CS-2 (Env B+CS2)

Figure 11 shows the time series built by taking the monthly averages of Env $\mathrm{B}+\mathrm{C}$ (in blue) and of Env B+CS2 (in red), considering the coastal points from 0 to $50 \mathrm{~km}$ from the coast. The limits are kept the same for both areas, in order to highlight the differences of the variability: SJ is characterised by a marked annual cycle, while the seasonal variations in NJ are much smaller. The linear fitting (solid straight lines) is also computed for the multi mission Env B+CS2lim time series (in green).

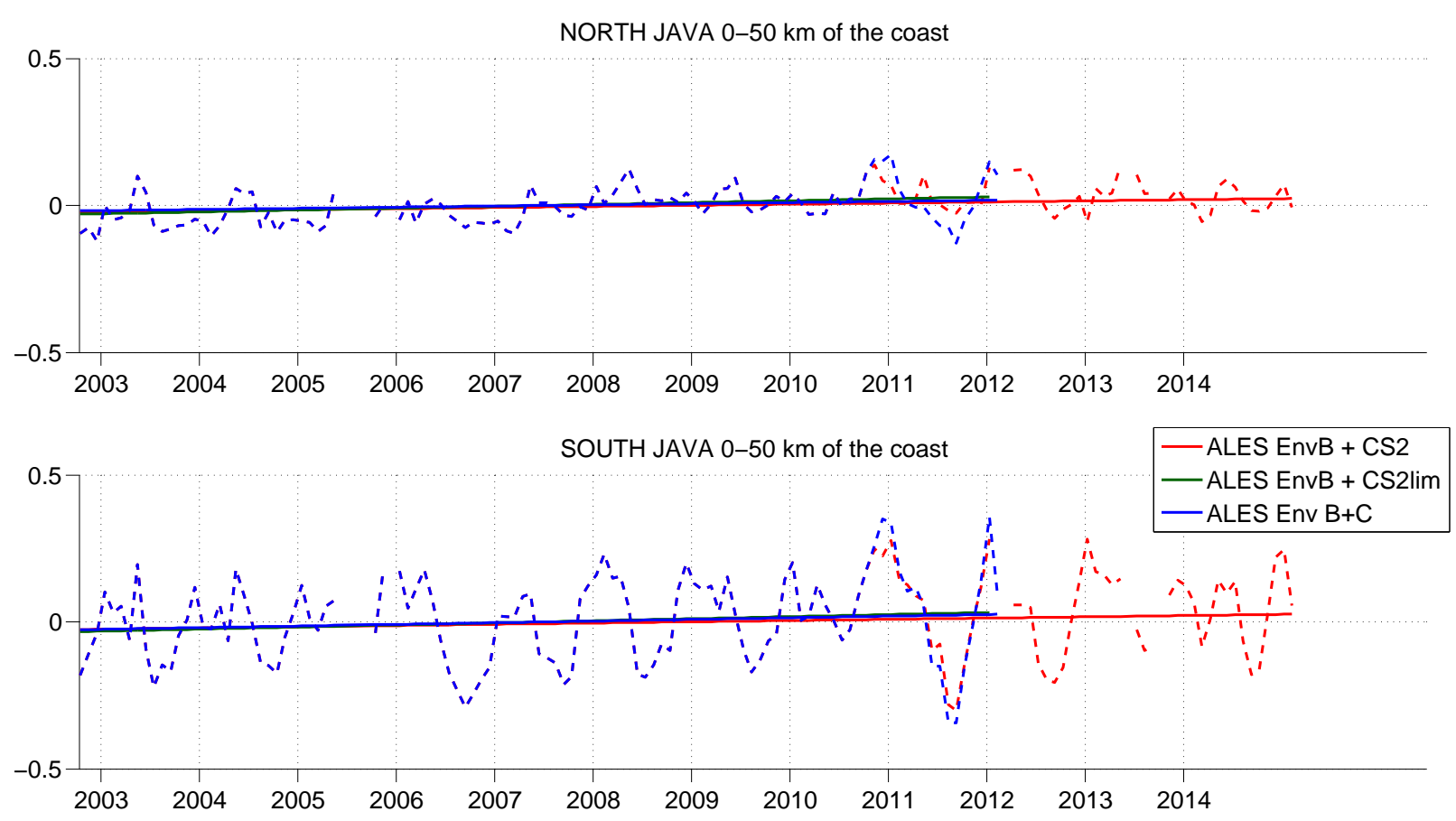

Figure 11: Time series in NJ and SJ at 0-50 km from the coast using Envisat B $+\mathrm{C}$ data (blue dashed line) or Envisat B+CS2 data (red dashed line). The straight lines show the linear fitting using Envisat $\mathrm{B}+\mathrm{C}$ data (blue), Envisat $\mathrm{B}+\mathrm{CS} 2$ data (red) and Envisat B+CS2 data only until the end of Envisat Phase C ("ALES Env B + CS2 lim", in green).

Firstly, the agreement of the time series from Env Phase C and CS-2 in the same months can be evaluated by computing the RMS of the difference, as reported in table 4 considering different distances from the coast. The RMS value is consistent, since numbers are similar in both the areas of study, although in NJ within $50 \mathrm{~km}$ of the coast the RMS is $0.5 \mathrm{~cm}$ higher. There is an increase of 1.2 to $1.5 \mathrm{~cm}$ in the coastal zone compared to the open ocean. This may be due to the accuracy of the corrections applied to both datasets, in particular the tide and MSS models, considering that the ground tracks of the two missions span different areas at different times. This could 
0-50 km 50-100 km 100-150 km

\begin{tabular}{llll} 
North Java $(\mathrm{m})$ & 0.063 & 0.048 & 0.048 \\
South Java $(\mathrm{m})$ & 0.058 & 0.046 & 0.047 \\
\hline
\end{tabular}

Table 4: RMS of the difference between the monthly time series of Env C and CS-2 in NJ and SJ at different distances from the coast.

\begin{tabular}{ccccc}
\hline & Env B & Env B+C & Env B+CS2lim & Env B+CS2 \\
Trend $(\mathrm{mm} / \mathrm{y})$ & $6.3 \pm 4.4$ & $3.9 \pm 3.4$ & $6.3 \pm 3.6$ & $3.8 \pm 2.6$ \\
Ann Ampl $(\mathrm{mm})$ & $25.0 \pm 12.9$ & $19.6 \pm 15.4$ & $21.3 \pm 12.6$ & $25.3 \pm 10.9$ \\
Semi Ampl (mm) & $25.0 \pm 10.4$ & $28.7 \pm 10.2$ & $25.7 \pm 9.9$ & $27.6 \pm 8.4$ \\
\hline
\end{tabular}

Table 5: Trend, annual amplitude and semiannual amplitude of the different sea level time series, using data within $50 \mathrm{~km}$ of the coast of NJ.

be seen particularly in NJ, due to the influence of internal tides that the models do not take into account.

Trends and amplitudes of annual and semiannual cycles are reported in tables 5 and 6 for NJ and SJ; the estimates and uncertainties are computed for all the time series listed previously.

The estimates of annual and semiannual cycle amplitude for Env B $+\mathrm{C}$ and Env $\mathrm{B}+\mathrm{CS} 2 \mathrm{lim}$ agree within $5 \mathrm{~mm}$ in both basins. Trends are difficult to estimate due to large uncertainties, but are positive for both Env B+C and Env B+CS2lim. Considering the trends of all combinations, the estimates are higher in the Env B years and decline with the extension of the time series up to 2015 (case Env B+CS2). In particular, the trends in the Env B years are in agreement with the trends ranging from 4 to $8 \mathrm{~mm} /$ year found in the region of study in the period 1993-2011(FenoglioMarc et al., 2012). The slower trends of Env+CS2 will be investigated in the next section.

The estimates confirm that SJ sees a strong annual cycle $(\sim 12-14 \mathrm{~cm})$, but also a pronounced semiannual cycle with an amplitude of roughly a third to a half of the annual amplitude. The semiannual and annual signals in NJ have similar amplitude of about 2 to $2.5 \mathrm{~cm}$. The annual pattern in the region is related to the reversal of the wind patterns associated with the Asian-Australian monsoon, as explained in section 2. The semiannual signal is related to the passage of coastally trapped Kelvin waves; they are the propagation of equatorial Kelvin waves generated in the Indian Ocean at the transition of the two monsoons, which propagate eastward hitting the coast of Sumatra (Sprintall et al., 2000; Sprintall and Révelard, 2014).

Using the longest time series (Env B+CS2), the variability is then computed at different distances from the coast for NJ and SJ in tables 7 and 8. Trend estimates in NJ are all positive and significant, while the ones in SJ have a higher uncertainty and therefore cannot be considered statistically significant. It is observed that the best estimates of both trends and seasonal cycle amplitude increase closer to the coast in SJ, while this is only true for the trend in NJ. While an argument based 
Env B Env B $+\mathrm{C} \quad$ Env B + CS2lim $\quad$ Env B $+\mathrm{CS} 2$

\begin{tabular}{ccccc} 
Trend $(\mathrm{mm} / \mathrm{y})$ & $8.9 \pm 7.6$ & $5.6 \pm 7.0$ & $7.0 \pm 6.6$ & $4.2 \pm 4.3$ \\
Ann Ampl $(\mathrm{mm})$ & $120.9 \pm 30.7$ & $138.1 \pm 30.9$ & $134.3 \pm 29.0$ & $130.5 \pm 24.5$ \\
Semi Ampl $(\mathrm{mm})$ & $38.7 \pm 23.3$ & $49.3 \pm 21.8$ & $43.9 \pm 21.0$ & $57.8 \pm 17.7$ \\
\hline
\end{tabular}

Table 6: Trend, annual amplitude and semiannual amplitude of the different sea level time series, using data within $50 \mathrm{~km}$ of the coast of SJ.

on the best estimates is here proposed, this coastal amplification is not statistically significant, considering the large error bars due to the short time series.

An increase in annual cycle amplitude towards the coast in SJ, can be linked to the physical processes responsible for the seasonality. Vinogradov et al. (2008) have shown how, at tropical latitudes, the annual and semi-annual signal is mostly driven by wind stress. The wind variation is indeed the main forcing on the intensity and direction of the Java Coastal Current (see section 2). Seasonal dynamics are altered along an $\mathrm{f} / \mathrm{H}$ gradient (where $\mathrm{f}$ is the potential vorticity and $\mathrm{H}$ is the depth) (Gill and Niiler, 1973), which, across SJ, is largely dominated by the depth variation. While in the shallower part the barotropic wind-driven seasonality will be predominant, as the wind acts on a thin layer, deeper contiguous areas may be more influenced by steric effects through the water coloumn (Vinogradov et al., 2008). Such coastal amplification has already been observed using coastal altimetry for the Norwegian Coastal Current in the Skagerrak Sea (Passaro et al., 2015a).

The possibility of higher sea level rise rates in the coastal zone on short time scales compared to the open ocean has long been debated and addressed as one of the key reasons for the development of coastal altimetry. Prandi et al. (2009) have concluded that 15 years of data are already sufficient to find an agreement between global coastal sea level rise measured by tide gauges and global sea level rise measured by altimetry, but regional differences may remain because of the higher interannual variability that is consistently observed along the coast. Recently (Melet et al., 2014) have shown marked increase in the variability of sea level, but also trends 20$30 \%$ higher than offshore, from altimetry with corrections optimised for the coastal zone, but using neither coastal retracking of standard altimetry nor SAR altimetry measurements. Our best estimates in NJ and SJ also show those higher coastal trends, but considering the temporal and spatial limits and the lack of statistical significance it is not possible to make firm conclusions. Further work is necessary, in a number of different regions and on a global scale, to elucidate the coastal vs offshore sea level issue. The natural extension of time series with time (and the extension back in time with reprocessing of old missions) is expected to help resolve this issue by reducing the level of uncertainty in the estimates.

\subsubsection{Indonesian Seas}

The trend and variability analysis is here extended to the Indonesian Seas as defined in figure 2, considering the longest time series generated in this study, i.e. Env B+CS2. Among the seas listed in the figure, only the ones where at least 10 satellite passes of Envisat and CS-2 are available for each month are chosen: Java, 


$$
\text { 0-50 km 50-100 km 100-150 km }
$$

\begin{tabular}{cccc} 
Trend $(\mathrm{mm} / \mathrm{y})$ & $3.8 \pm 2.6$ & $3.4 \pm 1.8$ & $3.2 \pm 1.6$ \\
Ann Ampl $(\mathrm{mm})$ & $25.3 \pm 10.9$ & $18.8 \pm 10.9$ & $26.2 \pm 10.9$ \\
Semi Ampl $(\mathrm{mm})$ & $27.6 \pm 8.4$ & $33.6 \pm 8.1$ & $33.3 \pm 8.2$ \\
\hline
\end{tabular}

Table 7: Trend, annual amplitude and semiannual amplitude of the multimission EnvB + CS2 time series, using data at different distances from the coast of NJ.

\begin{tabular}{cccc}
\hline & $0-50 \mathrm{~km}$ & $50-100 \mathrm{~km}$ & $100-150 \mathrm{~km}$ \\
Trend $(\mathrm{mm} / \mathrm{y})$ & $4.2 \pm 4.3$ & $3.4 \pm 4.3$ & $3.3 \pm 4.1$ \\
Ann Ampl $(\mathrm{mm})$ & $130.5 \pm 24.5$ & $112.3 \pm 22.0$ & $96.8 \pm 18.7$ \\
Semi Ampl (mm) & $57.8 \pm 17.7$ & $49.2 \pm 14.4$ & $36.8 \pm 11.7$ \\
\hline
\end{tabular}

Table 8: Trend, annual amplitude and semiannual amplitude of the multimission EnvB + CS2 time series, using data at different distances from the coast of SJ.

Flores, Banda and Ceram Seas. The results reported in table 9 and figure 12 are representative of the whole basins, regardless of the distance from the coast, because the SAR-altimetry coverage is not complete and uniform in most of the basins and because they are delimited mainly by bathymetric slopes rather than by coastlines.

Figure 12 indicates the switch between Envisat and CS-2 data with a vertical straight line. To add robustness to the analysis, the Env B+CS2 time series for each basin are compared with the sea level time series available from http://sealevel.colorado.edu (here called CU time series), generated considering the Jason ground tracks over the entire Indonesian Throughflow region and part of a dataset that is constantly monitored against a network of tide gauges and used to produce global mean sea level estimates (Nerem et al., 2010). This dataset, even if coming from a different processing and averaged on a wider area, is still useful for comparison because it includes data from different missions (TOPEX, Jason-1 and Jason-2) that sample repeated tracks without a discontinuity in time, such as the Envisat-CS-2 "switch".

The annual signal amplitude estimated in the entire Java Sea is larger than in the test area NJ. Indeed, the full area of the Java Sea is much wider and in particular includes a deeper area that borders the Makassar Strait. Moreover, the semiannual signal is stronger in Java than in the other internal seas. It has already been observed that the Kelvin waves that characterise the monsoon transitions can travel through the Lombok Strait and slow down the southward water transport in the Makassar Strait (Susanto and Song, 2015). From the semiannual amplitudes in the different seas, it is inferred that the waves propagate to the shallower Java Sea reaching the Makassar Strait, but do not influence the variability of the deeper Flores and Banda basins. This is in agreement with previous studies that concluded that the Kelvin waves exiting the Lombok Strait travel along the 100-m isobath (Pujiana et al., 2013).

The comparison with the $\mathrm{CU}$ time series and the good agreement between the curves proves that the decay in sea level seen in the CS-2 years is not an artefact. 


\begin{tabular}{ccccc}
\hline & Java & Flores & Banda & Ceram \\
Trend (mm/y) & $2.9 \pm 2.0$ & $2.9 \pm 2.4$ & $1.7 \pm 4.2$ & $3.3 \pm 3.2$ \\
Ann Ampl (mm) & $52.3 \pm 10.6$ & $59.1 \pm 10.1$ & $79.1 \pm 10.1$ & $78.4 \pm 11.8$ \\
Semi Ampl (mm) & $26.7 \pm 6.8$ & $4.2 \pm 6.3$ & $2.8 \pm 5.9$ & $6.3 \pm 7.4$ \\
\hline
\end{tabular}

Table 9: Trend, annual amplitude and semiannual amplitude of the multimission EnvB + CS2 time series for Java, Flores, Banda and Ceram seas.

Previously, Fenoglio-Marc et al. (2012) using altimetry in the region to compute trends in the period 1993-2011 observed how on interannual time scales the local sea level variability is strictly and homogeneously linked to the El Niño Southern Oscillation (ENSO) variability. The reason for the slowing trend is to be found in the strong La Niña event of 2010, which caused strong negative anomalies even in the global sea level (Cazenave et al., 2014), being the coldest ENSO event in the past eight decades (Boening et al., 2012).

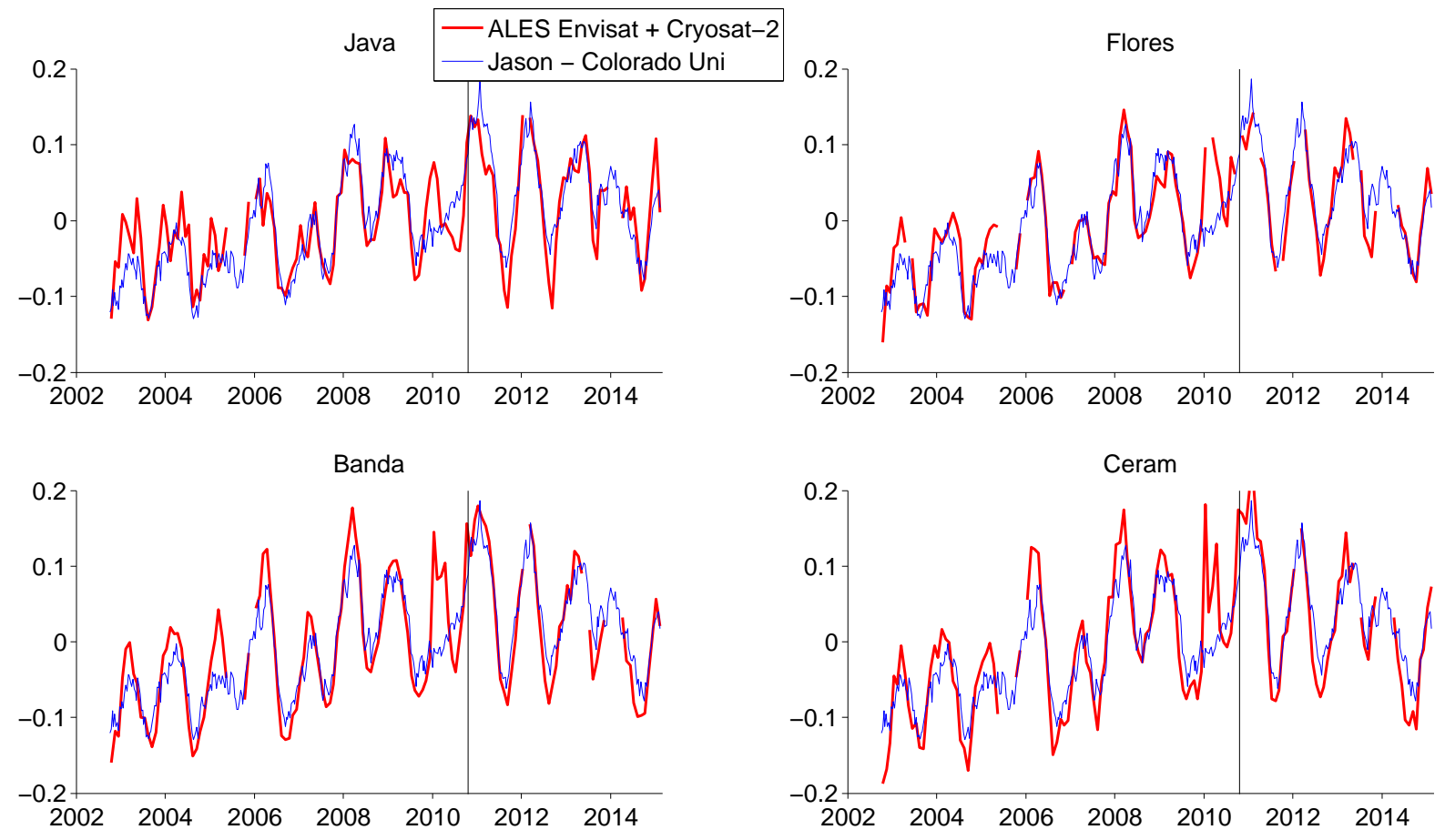

Figure 12: Multimission EnvB+CS2 time series (in red) and Jason-Colorado Uni time series (blue) for the Indonesian Seas. The vertical black line indicates the start of CS2 dataset.

\section{Conclusions}

This study has inter-compared Envisat (reprocessed with the ALES retracking algorithm) and CryoSat-2 (CS-2) SAR sea level anomalies in the Indonesian Seas. 
It demonstrated the cross-calibration of the new SAR altimetry data with ALESreprocessed coastal time series, which provides several years of observations that can help lower the level of uncertainty in the computation of trends and sea level periodicities.

The comparison has shown how SAR altimetry produces an improvement in coastal altimetry, thanks to better precision of the measurements and a smaller footprint. SAR altimetry from CS-2 is roughly $0.3 \mathrm{~cm}$ more precise than Envisat altimetry at $1 \mathrm{~Hz}$, even without any coastal-dedicated retracking of SAR waveforms. Overall, this comparison shows that the ocean product designed for CS-2 SAR can be applied successfully in combination with previous missions, despite the peculiar orbit characteristics of the satellite, designed mainly for the cryosphere. In Indonesia, it has been proven that the different orbit characteristics of Envisat and CS-2 do not have an influence on the variability of the spatially averaged sea level, therefore the DTU13 MSS model seems to be accurate enough even in areas that were previously unsampled. Considering that the results of the crossover analysis show similar statistics for Envisat also after the orbit change, it is concluded that the Envisat Phase C can be confidently used for sea level studies. Since there is still no agreement on the sea state bias model to be used for SAR altimetry, an empirical sea state bias correction ( $5 \%$ of the estimated SWH) was found. Although the sea state bias applied to standard altimetry relies on more complex models, it is important to note that this value differs slightly from the common approximation reported in the literature for pulse-limited altimetry ( $4 \%$ of the estimated $\mathrm{SWH}$ ).

This coastal dedicated strategy, using the sub-basin approach, has been able to detect the area of influence of the semiannual Kelvin waves generated in the Indian Ocean at the monsoon transitions, the coastal sea level rise in the years 2002-2010 and the effect of the strong La Niña event of 2010, which triggered lower sea level anomalies. The study has shown examples of the transition from deeper to shallower areas in terms of amplitude of the annual cycle, which is consistently higher in the presence of coastal currents such as in South Java. The availability of a global ALES dataset will allow the analysis on a wider scale in relation to the main coastal circulation patterns. It is harder and premature to derive any conclusion by comparing coastal and open-ocean sea level trends, since more years of observations are needed. The impact of the study in this case will definitely be enhanced by the extension of the ALES methodology to previous missions.

The work is particularly relevant in preparation for the processing of Sentinel-3 data, which will have full SAR altimetry coverage in the global ocean and will fly over ground-tracks that have never been sampled by previous altimeters (as in the case of CS-2 and Env C). The availability of global SAR altimetry with Sentinel-3 will allow the geographical expansion of this calibration exercise, but the validity of the consequent sea level analysis will still depend on the homogeneity and accuracy of the geophysical corrections applied to the dataset. 


\section{Citations}

\section{References}

Andersen, O. and Scharroo, R. (2011). Range and Geophysical Corrections in Coastal Regions and Implications for Mean Sea Surface Determination. In S. Vignudelli, A. Kostianoy, P. Cipollini, and J. Benveniste, editors, Coastal Altimetry, pages 103-146, Berlin Heidelberg. Springer-Verlag.

Boening, C., Willis, J. K., Landerer, F. W., Nerem, R. S., and Fasullo, J. (2012). The 2011 La Niña: So strong, the oceans fell. Geophys. Res. Lett., 39(19), L19602.

Bonnefond, P., Haines, B., and Watson, C. (2011). In situ absolute calibration and validation: a link from coastal to open-ocean altimetry. In S. Vignudelli, A. Kostianoy, P. Cipollini, and J. Benveniste, editors, Coastal Altimetry, pages 259-96, Berlin Heidelberg. Springer-Verlag.

Bonnefond, P., Exertier, P., Laurain, O., T., G., and Femenias, P. (2013). Corsica: A multi-mission absolute calibration site. In Proceeding of 20 Years of Progress in Radar Altimetry, ESA-SP-710.

Cazenave, A., Dieng, H.-B., Meyssignac, B., von Schuckmann, K., Decharme, B., and Berthier, E. (2014). The rate of sea-level rise. Nature Clim. Change, 4(5), $358-361$.

Cipollini, P. (2011). A new parameter to facilitate screening of coastal altimetry data and corrections. presented at the 5th Coastal Altimetry Workshop, San Diego, USA, available from http://www.coastalt.eu/files/sandiegoworkshop11/poster/ P08_Cipollini_Coastal_Proximity.pdf.

Dinardo, S. and Benveniste, J. (2013). Guidelines for the SAR (DelayDoppler) L1b Processing. ESA document, reference XCRY-GSEG-EOPSTN-14-0042, available from https : //wiki.services.eoportal.org/tikidownload_wiki_attachment.php?attId $=2540$.

Durand, J. and Petit, D. (2011). The Java Sea Environment, pages 15-38. Indonesian Agency for Agriculture Research and Development, Jakarta, Indonesia, available from http://horizon.documentation.ird.fr/exl-doc/pleins $s_{t}$ extes/divers0906/42768.pdf.

Fenoglio-Marc, L., Schöne, T., Illigner, J., Becker, M., Manurung, P., and Khafid (2012). Sea level change and vertical motion from satellite altimetry, tide gauges and GPS in the Indonesian region. Mar. Geod., 35(sup1), 137-150.

Fenoglio-Marc, L., Dinardo, S., Scharroo, R., Roland, A., Sikiric, M. D., Lucas, B., Becker, M., Benveniste, J., and Weiss, R. (2015). The German Bight: a validation of Cryosat-2 altimeter data in SAR mode. Adv. Space Res., 55(11), 2641-2656.

Gill, A. E. and Niiler, P. P. (1973). The theory of seasonal variability in the ocean. Deep Sea Res., 20, 141-177. 
Gordon, A. L. (2005). The Indonesian Seas. Oceanography, 18(4), 14.

Iskandar, I., Tozuka, T., and Sasaki, H. (2006). Intraseasonal variations of surface and subsurface currents off Java as simulated in a high-resolution ocean general circulation model. J. Geophys. Res.-Oceans, 111, C12015.

Iskandar, I., Masumoto, Y., and Mizuno, K. (2014). Coherent intraseasonal oceanic variations in the eastern equatorial Indian Ocean and in the Lombok and Ombai Straits from observations and a high-resolution OGCM. J. Geophys. Res.-Oceans, 119(2), 615-630.

Jin, S., Luo, O., and Gleason, S. (2009). Characterization of diurnal cycles in ZTD from a decade of global GPS observations. J. Geodesy, 83(6), 537-545.

Labroue, S., Boy, F., Picot, N., Urvoy, M., and Ablain, M. (2012). First quality assessment of the Cryosat-2 altimetric system over ocean. Adv. Space Res., 50(8), $1030-1045$.

Liu, J., Chen, R., Wang, Z., and Zhang, H. (2011). Spherical cap harmonic model for mapping and predicting regional TEC. GPS solutions, 15(2), 109-119.

Lyard, F., Lefevre, F., Letellier, T., and Francis, O. (2006). Modelling the global ocean tides: Modern insights from FES2004. Ocean Dynam., 56(5-6), 394-415.

Melet, A., Nonti, M., Chide, B., Meyssignac, B., and Birol, F. (2014). Comparing coastal and open ocean sea level variability and trend from altimetric data. presented at the Ocean Surface Topography Science Team meeting, Konstanz, Germany, available from http://meetings.aviso.altimetry.fr/fileadmin/user_upload/tx_ausyclsseminar / files/29Red1615-6_OSTST_2014_Melet_v2.pdf.

Nerem, R., Chambers, D., Choe, C., and Mitchum, G. (2010). Estimating mean sea level change from the TOPEX and Jason altimeter missions. Mar. Geod., 33(S1), $435-446$.

Palanisamy, H., Cazenave, A., Delcroix, T., and Meyssignac, B. (2015). Spatial trend patterns in the Pacific Ocean sea level during the altimetry era: The contribution of thermocline depth change and internal climate variability. Ocean Dynam., 65(3), 341-356.

Passaro, M., Cipollini, P., Vignudelli, S., Quartly, G., and Snaith, H. (2014). ALES: A multi-mission subwaveform retracker for coastal and open ocean altimetry. Remote Sens. Environ., 145, 173-189.

Passaro, M., Cipollini, P., and Benveniste, J. (2015a). Annual sea level variability of the coastal ocean: The Baltic Sea-North Sea transition zone. J. Geophys. Res.-Oceans, 120(4), 3061-3078.

Passaro, M., Fenoglio-Marc, L., and Cipollini, P. (2015b). Validation of significant wave height from improved satellite altimetry in the German Bight. IEEE Trans. Geosci. Remote Sensing, 53(4), 2146-2156. 
Ponte, R. M. and Ray, R. D. (2002). Atmospheric pressure corrections in geodesy and oceanography: A strategy for handling air tides. Geophys. Res. Lett., 29(24), $6-1$.

Prais, S. J. and Winsten, C. B. (1954). Trend estimators and serial correlation. Chicago: Cowles Commission Discussion Paper No.383.

Prandi, P., Cazenave, A., and Becker, M.(2009). Is coastal mean sea level rising faster than the global mean? A comparison between tide gauges and satellite altimetry over 1993-2007. Geophys. Res. Lett., 36, L05602.

Pujiana, K., Gordon, A. L., and Sprintall, J. (2013). Intraseasonal Kelvin wave in Makassar Strait. J. Geophys. Res.-Oceans, 118(4), 2023-2034.

Quartly, G. D. (1998). Determination of oceanic rain rate and rain cell structure from altimeter waveform data. Part I: Theory. J. Atmos. Ocean Tech., 15(6), $1361-1378$.

Raney, R. K. (1998). The delay/doppler radar altimeter. IEEE Trans. Geosci. Remote Sensing, 36(5), 1578-1588.

Ray, C., Martin-Puig, C., Clarizia, M. P., Ruffini, G., Dinardo, S., Gommenginger, C., and Benveniste, J. (2015). SAR altimeter backscattered waveform model. IEEE Trans. Geosci. Remote Sensing, 53(2), 911-919.

Sprintall, J. and Révelard, A. (2014). The Indonesian Throughflow response to Indo-Pacific climate variability. J. Geophys. Res.-Oceans, 119(2), 1161-1175.

Sprintall, J., Gordon, A. L., Murtugudde, R., and Susanto, R. D. (2000). A semiannual Indian Ocean forced Kelvin wave observed in the Indonesian seas in May 1997. J. Geophys. Res.-Oceans, 105(C7), 17217-17230.

Sprintall, J., Chong, J., Syamsudin, F., Morawitz, W., Hautala, S., Bray, N., and Wijffels, S. (1999). Dynamics of the South Java Current in the Indo-Australian Basin. Geophys. Res. Lett., 26(16), 2493-2496.

Strassburg, M., Hamlington, B., Leben, R., Manurung, P., Lumban Gaol, J., Nababan, B., Vignudelli, S., and Kim, K.-Y. (2014). Sea level trends in South East Asian Seas (SEAS). Climate Past Discuss., 10(5), 4129-4148.

Susanto, R. D. and Song, Y. T. (2015). Indonesian throughflow proxy from satellite altimeters and gravimeters. J. Geophys. Res.-Oceans, 120(4), 2844-2855.

Syamsudin, F. and Kaneko, A. (2013). Ocean variability along the southern coast of Java and Lesser Sunda Islands. Journal of Oceanography, 69(5), 557-570.

Stammer, D., R. D. Ray, O. B. Andersen, B. K. Arbic, W. Bosch, L. Carrere, Y. Cheng, B. D. Dushaw, G. D. Egbert, S. Y. Erofeeva, H. S. Fok, M. Green, S. Griffiths, B. Killer, M. A. King, F. G. Lemoine, S. B. Luthcke, F. Lyard, M. Mller, L. Padman, J. Richman, J. Shriver, C. K. Shum, and E. Taguchi (2014). 
1

Accuracy assessment of global barotropic ocean tide models. Rev. Geophys., 52(3), 243-282.

Vignudelli, S., Kostianoy, A. G., Cipollini, P., and Benveniste, J. (2011). Coastal altimetry. Berlin Heidelberg. Springer-Verlag. doi: 10.1007/978-3-642-12796-0.

Vinogradov, S. V., Ponte, R. M., Heimbach, P., and Wunsch, C. (2008). The mean seasonal cycle in sea level estimated from a data-constrained general circulation model. J. Geophys. Res., 113, C03032.

Walsh, E. J. (1982). Pulse-to-pulse correlation in satellite radar altimeters. Radio Sci., 17(4), 786-800. 
Reviewer \#1: The authors have addressed all my comments, so I would suggest to accept it as is.

The authors are thankful for this final remark.

Reviewer \#3: From a viewpoint of remote sensing studies, I have no objections to publishing this manuscript.

Meanwhile, as a physical oceanographer, I still think several points should be modified (or, at least mentioned).

The authors are thankful to Reviewer \#3 for the additional discussion.

In the following answers to points 1 and 3, we have produced the requested figures, but we believe that their inclusion is not much more helpful to the purpose of the paper.

We agree with the reviewer on point 2 and we have added the relevant discussion to the paper.

The new paragraphs added to the manuscript are highlighted in red.

1)

I'm almost satisfied with comments on errors of the tidal correction, but additional cares should be taken when comparing CS-2 and ENV for the S2 constituent.

As shown in Fig.6, the tidal phase differences of the $\mathrm{S} 2$ constituent between crossover points are fixed for the sun-synchronous ENV, while they are not for CS-2.

Similarly, for constituents whose periods are close to 24 hours such as K1 and P1, tidal phase differences between crossover points are nearly constant within 10 days.

These phase differences would introduce differences between ENV and CS-2 and also NJ and SJ.

Distributions of tidal phase differences as in Fig.6 (in NJ and SJ, respectively) may help readers to understand tidal errors.

We assume that the reviewer is referring to the crossover statistics. We would prefer not to overload the paper with additional figures, given the indications from other reviewers. For this discussion, we attach a figure that reproduces Fig. 6 considering on the $x$-axis the phase difference of the crossovers w.r.t. the S2 constituent, which is the one with the highest uncertainty.

The tidal phase differences of the crossovers is fixed not only for the case "Env vs Env", but also for the case "CS-2 vs CS-2".

The crossovers of Envisat vs CS-2 span the whole range of phase differences and also the whole geographic domain (see later). This is now highlighted in a new paragraph in section 4.2. This, in our opinion, confirms the validity of the calibration based on the crossover differences. Moreover, the single-mission crossovers, at least for S2, have a very similar phase difference both in NJ and SJ.

We agree with the reviewer that the tide issue is particularly challenging, but this has been discussed in the previous review and we believe that it could be treated with particular care in a separate study.

2) I do understand reasons to choose $1 \mathrm{~Hz}$ sampling, and do agree that $\odot .1 \mathrm{~Hz}$ sampling would smooth the Java Coastal Current.

Meanwhile, the crossover analysis requires no significant oceanic variations within 10 days.

Is it really realistic to expect a stable Java Coastal current within 10 days in $7-\mathrm{km}$ spatial scale?

In other words, variations of the Java Coastal Current would be another source 
of crossover differences, and thus comparisons between $\mathrm{NJ}$ and SJ.

We agree with the reviewer that the JCC should be mentioned as a source of additional crossover differences. Nevertheless the available literature confirms that the variability within 10 days would be very limited. A paragraph mentioning the issue and the relative literature research is added in section 4. 2 .

3)

Since the orbit patterns of ENV and CS-2 are so different, readers would like to know typical spatial distributions of crossover points.

I'm just afraid that crossover points of ENV are much sparser than those of CS2(, which may miss important features such as 5-day meanders of the Java Coastal Current!).

For the benefit of the discussion, we attach a map of the crossover distribution (considering the 10-day limit). We agree with the reviewer that the different missions show a different distribution pattern, although this is already shown in Figure 6. The fact that the crossovers of CS2 vs CS2 do not include the coast of SJ is already discussed with figures 6 and 8, as well. We would share the reviewer's view, if the focus was on the analysis of single mission crossovers. But the development of the paper (i.e., the cross-calibration) is based on the multimission crossovers (EnvC vs CS2), which are uniformly distributed along the domain, both in time and space. This key information is already highlighted and discussed in the paper. An additional comment is added in Section 4.2 and the latitudinal bands of the monomission crossovers are now specified.

We would prefer to avoid adding this additional figure, to avoid overloading. Nevertheless, if both the reviewer and the editor prefer, we would accept the criticism. 


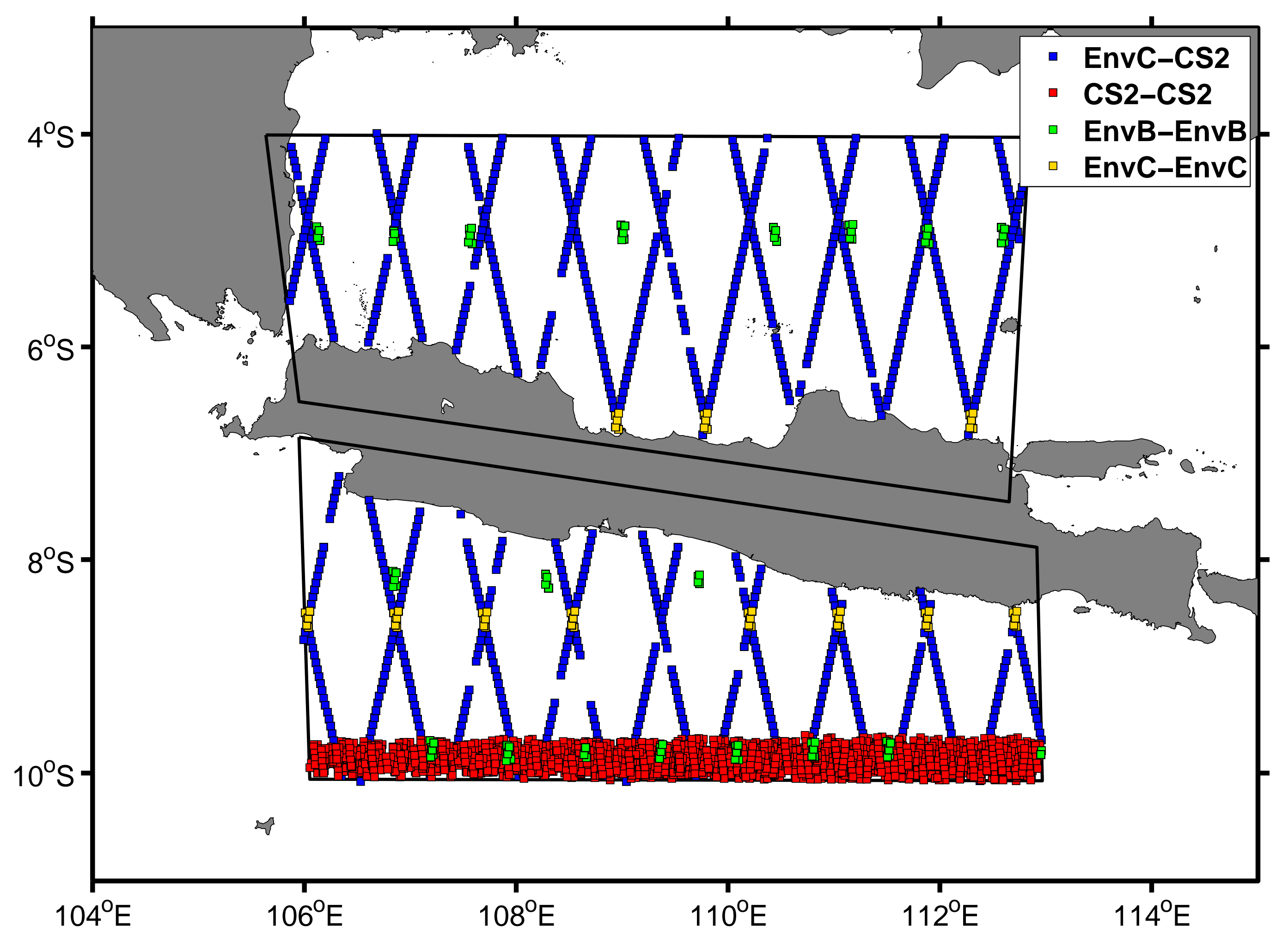



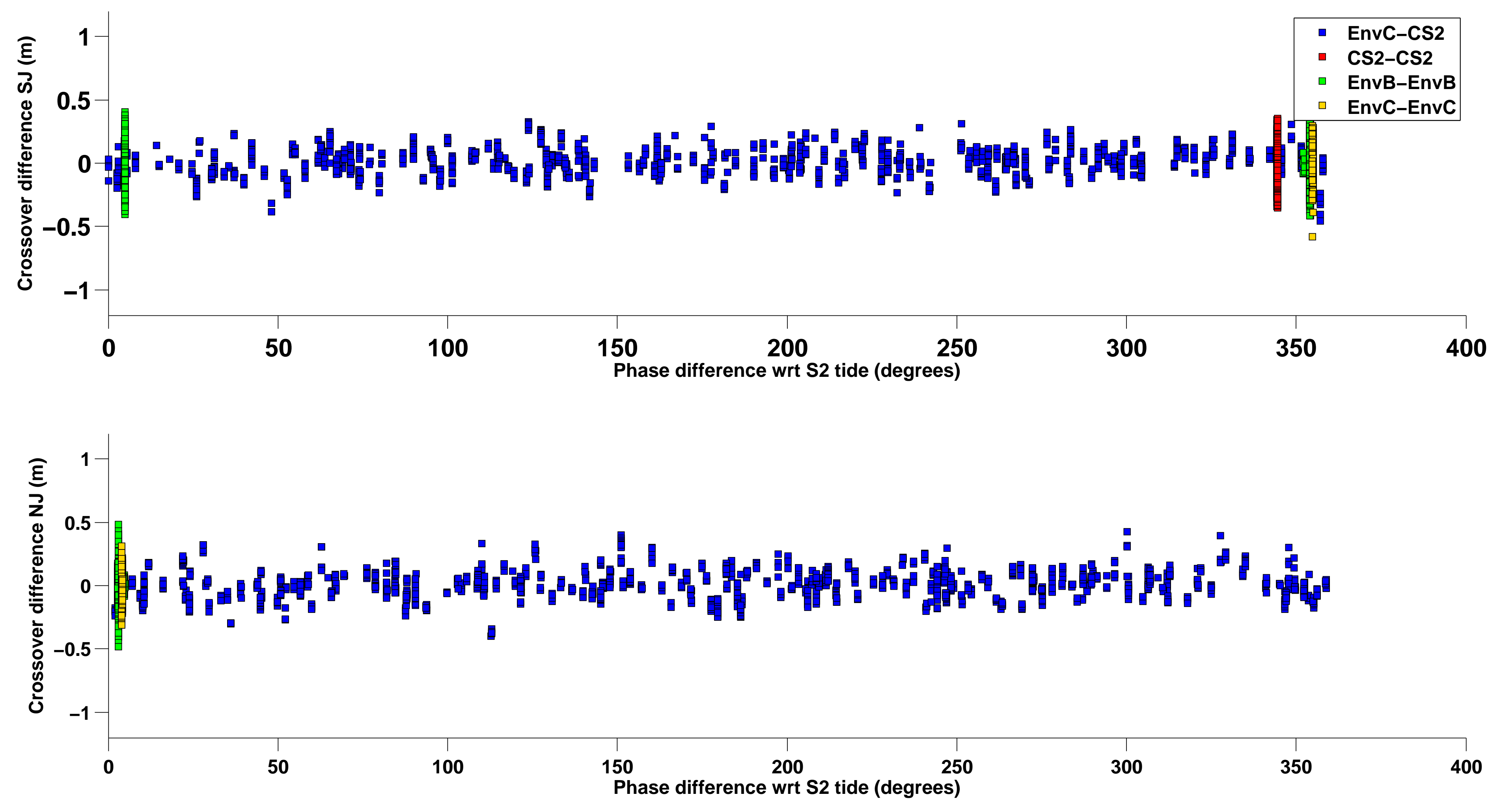
Highlights

\section{HIGHLIGHTS}

- First sea level study that combines SAR altimetry with coastal-dedicated standard altimetry reprocessing

- Cryosat-2`s altimeter is $0.3 \mathrm{~cm}$ more precise than Envisat`s altimeter for sea level estimation at $1 \mathrm{~Hz}$

- Seasonal variability and trends of the sea level revealed in the Indonesian Seas at a sub-regional scale 
Click here to download LaTeX Source Files: jasr_Passaro_UNIX.tex 